University of Louisville

ThinkIR: The University of Louisville's Institutional Repository

$8-2020$

\title{
An investigation of the effect of contour process parameters on the surface roughness and dimensionality of overhanging features in 17-4 stainless steel.
}

Katherine Schneidau

University of Louisville

Follow this and additional works at: https://ir.library.louisville.edu/etd

Part of the Mechanical Engineering Commons

\section{Recommended Citation}

Schneidau, Katherine, "An investigation of the effect of contour process parameters on the surface roughness and dimensionality of overhanging features in 17-4 stainless steel." (2020). Electronic Theses and Dissertations. Paper 3513.

https://doi.org/10.18297/etd/3513

This Master's Thesis is brought to you for free and open access by ThinkIR: The University of Louisville's Institutional Repository. It has been accepted for inclusion in Electronic Theses and Dissertations by an authorized administrator of ThinkIR: The University of Louisville's Institutional Repository. This title appears here courtesy of the author, who has retained all other copyrights. For more information, please contact thinkir@louisville.edu. 
AN INVESTIGATION OF THE EFFECT OF CONTOUR PROCESS PARAMETERS ON THE SURFACE ROUGHNESS AND DIMENSIONALITY OF OVERHANGING FEATURES IN 17-4 STAINLESS STEEL

\author{
By \\ Katherine Schneidau \\ B.S., University of Louisville, 2019
}

\author{
A Thesis \\ Submitted to the Faculty of \\ J.B. Speed School of Engineering, University of Louisville \\ in Partial Fulfillment of the Requirements \\ for the Degree of \\ Master of Science \\ in Mechanical Engineering \\ Department of Mechanical Engineering \\ University of Louisville, \\ Louisville, Kentucky
}

August 2020 
Copyright 2020 by Katherine Schneidau

All rights reserved 

AN INVESTIGATION OF THE EFFECT OF CONTOUR PROCESS PARAMETERS ON THE SURFACE ROUGHNESS AND DIMENSIONALITY OF OVERHANGING FEATURES IN 17-4 STAINLESS STEEL

By

Katherine Grace Schneidau

B.S., University of Louisville, 2019

A Thesis Approved on

July 23,2020

by the following Thesis Committee:

Thesis Director

Dr. Thomas A. Berfield

Thesis Co-Director

Dr. Thomas L. Starr

Third Committee Member

Dr. Li Yang 


\section{ACKNOWLEDGEMENTS}

I would like to thank Ed Tackett, Gary Graf, Tim Gornet, and Dr. Thomas Starr for the guidance and opportunities they have given over the past three years that has shaped my Additive Manufacturing knowledge base. To my thesis advisor Dr. Thomas Berfield, who has helped me throughout my thesis journey, especially the last few months of pushing forward to complete my thesis in time.

I would also like to thank my fellow cooperative engineering interns and graduate research assistants, Sean Dobson, Kayla Montgomery, and Justin Gilham for all their assistance over the past year while I completed my thesis.

To say this journey has not had its share of bumps would be an understatement, but one that I would never choose to go a different way. I have grown not only as a student and young adult, but as an emerging member of the Additive Manufacturing workforce, and I look forward to expanding my understanding of Additive Manufacturing for years to come.

Thank you. 


\section{ABSTRACT \\ AN INVESTIGATION OF THE EFFECT OF CONTOUR PROCESS PARAMETERS ON THE \\ SURFACE ROUGHNESS AND DIMENSIONALITY OF OVERHANGING FEATURES IN 17-4 \\ STAINLESS STEEL}

Katherine G. Schneidau

July 27, 2020

The relationship between varying contour settings and part geometry provides insight into the attainable surface roughness and dimensional accuracy of parts fabricated in 17-4 stainless steel via selective laser melting (SLM). Varying the contour settings of laser power (W), scan speed ( $\mathrm{mm} / \mathrm{s})$, and beam offset $(\mathrm{mm})$ for unsupported inclined bars. The utilization of a coordinate measuring machine (CMM) and surface profilometer quantified the dimensional accuracy and average surface roughness $(R a)$ for upface, downface, and topface surfaces. Adjusting the laser power and scan speed had minimal affect to surface roughness compared to part geometry. Part dimensionality was affected by the incline angle, laser power, and scan speed. Lower energy densities $(\mathrm{J} / \mathrm{mm})$ resulted in oversized parts, while higher energy densities resulted in undersized dimensions. A clear relationship between varying contour settings and part geometry with the dimensionality and surface roughness of 17-4 fabricated benchmark parts was found. 
TABLE OF CONTENTS

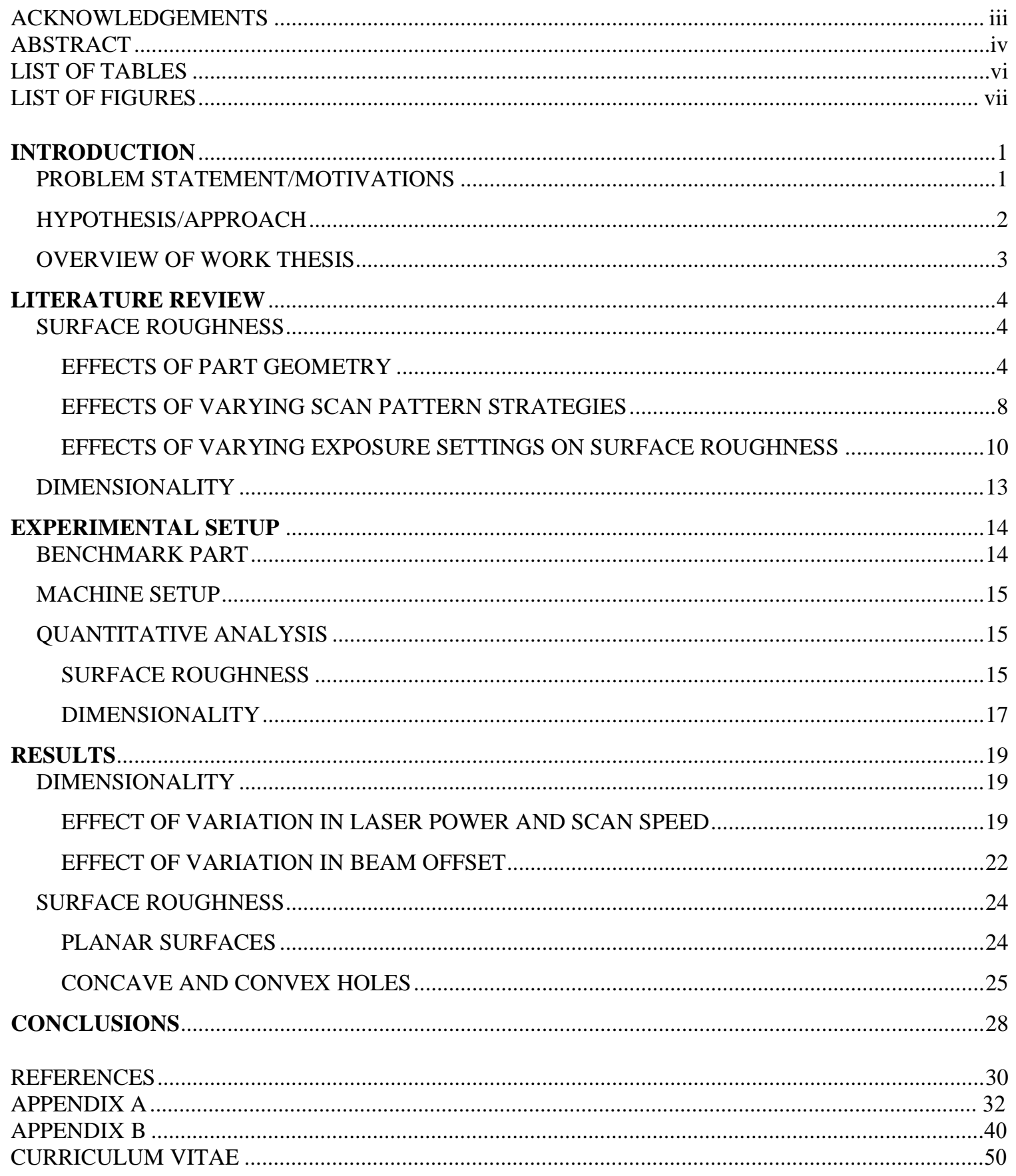




\section{LIST OF TABLES}

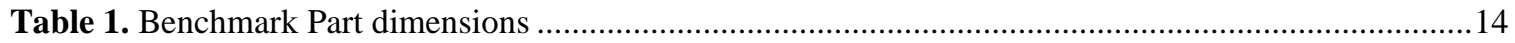

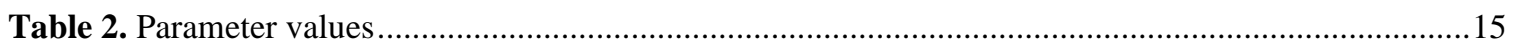

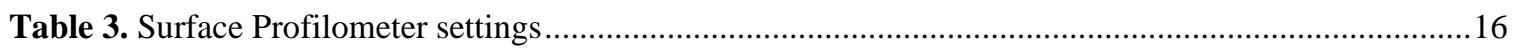

Table 4. Nomenclature for surface angle based upon surface location and overhanging bar incline angle..16

Table 5. CMM dimension measurements for contour sets 2 through 5, with power and speed settings noted, along with nominal values for both width and thickness of benchmark v2 overhang bars. .......... xxxii Table 6. Measurement deviations from CAD for v1 benchmark part with varying beam offset settings.

XXXiii

Table 7. Downface flatness callout from CMM program for contour sets 2 through 5 for all overhang bars on specimen.

.$x x x i x$

Table 8. Surface profilometer measurements of Ra for each feature on benchmark specimen v2 built with contour set 2 .

Table 9. Surface profilometer measurements of Ra for each feature on benchmark specimen v2 built with contour set 3 . xlii

Table 10. Surface profilometer measurements of Ra for each feature on benchmark specimen v2 built with contour set 4 . .xlv

Table 11. Surface profilometer measurements of Ra for each feature on benchmark specimen v2 built with contour set 5 . xlviii 


\section{LIST OF FIGURES}

Figure 1. Process map of simulated parameter settings for 316L stainless steel utilizing constraints (Tran \& Lo, 2019)

Figure 2. Average surface roughness $(R a)$ of the incline angles' top surface parallel $(\beta)$ and perpendicular $(\alpha)$ to the scan direction for 316L stainless steel (Ni et al., 2019).

Figure 3. Geometry and surface notation of fabricated benchmark part (Subbaian Kaliamoorthy et al., 2020).

Figure 4. Surface Roughness measurements for benchmark part in terms of surface plane (Subbaian Kaliamoorthy et al., 2020)

Figure 5. Ra of overhang angles $30^{\circ}, 45^{\circ}, 60^{\circ}$, and $75^{\circ}$. (Fox et al., 2016).

Figure 6. a) Path lines for bi-directional scan. b) path line for a $67^{\circ}$ rotational stripe. c) height map for no rotation, bi-directional scan and d) height map for stripe path with rotation (DePond et al., 2018).

Figure 7. Surface roughness values, taken at each layer, with and without a $67^{\circ}$ rotational stripe (DePond et al., 2018)

Figure 8. Overhang part surface nomenclature and layer slice denoting the activation areas of different exposure settings.

Figure 9. Arithmetical mean height $(S a)$ of top surface of hollow cube with different laser powers for upskin and downskin on overhang layers (DePond et al., 2018).

Figure 10. Surface morphology of parts built at varying laser power, scan speed, and hatch distance (Deng et al., 2020).

Figure 11. Benchmark geometry of (a) v1 and (b) final version, v2.

Figure 12. Standard nomenclature for part surfaces based on the incline angle from the build plate top surface.

Figure 13. Measurement locations for concave and convex hole features on each overhanging bar, denoted in the surface angle nomenclature presented in Figure $\mathbf{1 2}$

Figure 14. (a) measured width and (b) measured thickness of the v2 overhanging bar for varying laser power and scan speed settings correlating to contour sets 2 through 5 . .20

Figure 15. $30^{\circ}$ downskin sagging for (a) contour set 2 (b) set 3, (c) set 4, and (d) set 5 .

Figure 16. Flatness of the downface surfaces for contour sets 2 through 5 from the CMM program report.

Figure 17. Point cloud color mapping of v2 overhang specimen at (a) $30^{\circ}$, (b) $50^{\circ}$, (c) $70^{\circ}$, and (d) $90^{\circ} \ldots .22$

Figure 18. (a) Thickness and width measurement deviations of $v 1$ specimen for beam offsets of $0.08 / 0$ and

$0.1 / 0.08$ 
Figure 19. Surface roughness data for upface, downface, and topface surfaces of the v 2 overhanging bar across contour sets 2 through 5 .

Figure 20. Effect on surface finish for hole features with (a) varying incline angle for a single parameter measured at $180^{\circ}$ concave, and (b) varying parameter for a single incline angle at $50^{\circ}$. .26

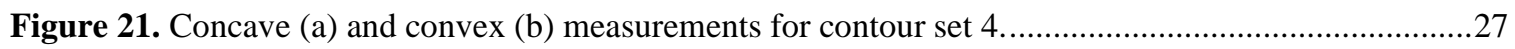

Figure 22. Point cloud visual display for contour set 2 with point cloud deviations at (a-b) $30^{\circ}$ (c-d) $50^{\circ}$, (e-f) $70^{\circ}$, and (g-h) $90^{\circ}$ overhang planes....... ..xxxiv

Figure 23. Point cloud visual display for contour set 3 with point cloud deviations at (a-b) $30^{\circ}$ (c-d) $50^{\circ}$, (e-f) $70^{\circ}$, and (g-h) $90^{\circ}$ overhang planes. .xxxvi

Figure 24. Point cloud visual display for contour set 4 with point cloud deviations at (a-b) $30^{\circ}$ (c-d) $50^{\circ}$, (e-f) $70^{\circ}$, and (g-h) $90^{\circ}$ overhang planes. xxxvii

Figure 25. Point cloud visual display for contour set 5 with point cloud deviations at (a-b) $30^{\circ}$ (c-d) $50^{\circ}$, (e-f) $70^{\circ}$, and (g-h) $90^{\circ}$ overhang planes. xxxviii 


\section{INTRODUCTION}

\section{PROBLEM STATEMENT/MOTIVATIONS}

Additive Manufacturing (AM) is the next step in advancing the field of manufacturing by enabling the ability to achieve geometries not attainable through traditional subtractive manufacturing due to the layerby-layer process of adding material rather than removing them. For over 25 years the Wohler's Report (Wohlers et al., 2018) has been following the trends of AM. In their 2018 report, Wohler Associates discuss the growth of AM products and services, which averaged a growth of $24.9 \%$ over the previous four years. In this paper, laser powder bed fusion $(\mathrm{L}-\mathrm{PBF})$ of metals is discussed with respect to the limitations and concerns for producing parts fabricated through this process, also called Selective Laser Melting (SLM). The main concern is how surface roughness and dimensionality of parts can be altered through changes to the process parameters (laser power, scan speed, beam offset). Additional concerns that can be evaluated further from the results of this experiment includes how parameter changes can affect part performance (fatigue properties) and post-processing operations, such as dimensional machining, and surface operations.

The importance of this research stems from how surface roughness has been found to affect the fatigue performance of parts. The consensus from a literature review of metal AM structure mechanical performance is clear: when there is a rougher surface, the likelihood of cracks propagating from the surface greatly increases. Gockel, Sheridan, Koerper, and Whip (2019) found such results for AM metal fatigue performance and noticed that for the right laser power and scan speed settings the surface roughness was controlled, reducing surface crack propagation. When the potential for surface crack propagation decreases, the primary initiator of fracture moves to the presence of sub-surface porosity or inclusions. Adjusting the presence of sub-surface porosity and decreasing the surface roughness of a part can contribute to a longer fatigue life. 
As more research continues for SLM, trends between processing parameters and fabricated part quality will be further understood. Since there are over 3600 variables that can be adjusted to create an almost endless array of processing parameters, parameter development can be difficult. A parameter setting may produce excellent mechanical properties and build fast but come at the cost of surface finish or roughness.

The surface roughness of a selective laser melting (SLM) fabricated part is influenced by the overhang angles of the geometry, scan strategy (stripe, checkerboard, bi-directional/meander), and exposure settings (laser power, scan speed, hatch distance). This research will examine the relationship between surface roughness and part dimensionality for varying parameter settings. Understanding how to control surface roughness can help minimize crack propagation for fatigue property influence and part life (Solberg et al., 2019).

\section{HYPOTHESIS/APPROACH}

The focus of this research is on the relationship between contour parameter settings such as laser power, scan speed, and beam offset on the surface roughness and dimensionality of overhanging features. From previous work in SLM research, surface roughness has been found to be adjusted by process parameters, part geometry, and scan strategy. This study will focus on the contour settings, of various inclined bars with holes. The benchmark part described in Section 3.1 was created to quantify the effect of unsupported overhanging angles, concave, and convex holes on surface roughness and dimensionality for varying contour settings.

It is expected that adjusting the laser power and scan speed of the contour will either decrease or increase the surface roughness as the overhanging bars move down from $90^{\circ}$ to $30^{\circ}$, relative to the build plate surface. Specifically, increasing the energy that goes into the material upon scanning will adjust the melt pool size and subsequently the surface roughness and dimensionality. The beam offset of the contour settings will control the dimensionality of the final part, with increasing the beam offset resulting in a larger part than the supplied CAD.

Through the literature review it is clear there is a relationship between surface roughness and dimensional accuracy with varying parameter settings for different materials. While materials such as Ti6Al-4V and 316 SS have been much studied, there is little research published on these relationships for 174 stainless steel, specifically when looking at the contour or outline settings. The goal of this research is to 
establish a relationship trend of the dimensionality and surface roughness of various overhang geometries for 17-4 stainless steel with contour parameter settings for parts fabricated by the Selective Laser Melting (SLM) process.

\section{OVERVIEW OF WORK THESIS}

All work has been divided into multiple sections to ensure clarity. In the next section, Section 2, an overview of the current state of knowledge in the AM metal field is presented along with reviews of previous studies that explore the influences on surface roughness and dimensionality. The literature review is broken into sub-sections that evaluate the effect a single variable has on surface roughness and dimensionality from part geometry, scan strategy, and parameter values. Section 3 contains the experimental approach and includes the equipment used, material, and the parameter settings for each specimen built. Section 4 contains a report and analysis of dimensionality and surface roughness testing of each specimen with all conclusions stated in Section 5. Mechanical testing was not included in this analysis due to time constraints, however it would be beneficial to include in future work. 
LITERATURE REVIEW

\section{SURFACE ROUGHNESS}

\section{EFFECTS OF PART GEOMETRY}

Research on relationships between process parameters and surface roughness has been conducted on multiple other material systems from Inconel 718 and 316 stainless steel to Ti6Al-4V. Adjusting either laser power, scan speed, or hatch spacing can change an excellent mechanical property to excellent surface finish, but adjusting the values result in the presence of sub-surface porosity to increase or parts being less dense as the focus is to have high quality looking parts. Each material has different relationships with parameter settings, and a range of setting combinations result in optimal part quality in terms of density, surface roughness, and mechanical properties. Changes to each will get you "too cold", "too hot" or "just right" part quality depending on if you prefer mechanical property, surface finish, or density characteristics. With over 3600 combinations for scan speed and laser power settings along, utilizing an artificial neural network can help run simulations, and will allow a process map to be used for determining good parameter windows (Tran \& Lo, 2019). These simulations have an algorithm that is developed based on the fabrication of samples and inputting the relationships found between variables such as laser power, scan speed, hatch

distance, and scan strategy. The development of these neural networks take time to develop as there they are based upon examining the variable relationships through fabrication first. Figure 1 shows a process map of 316L stainless steel used to determine optimal parameters to maximize density and reduce surface roughness. 


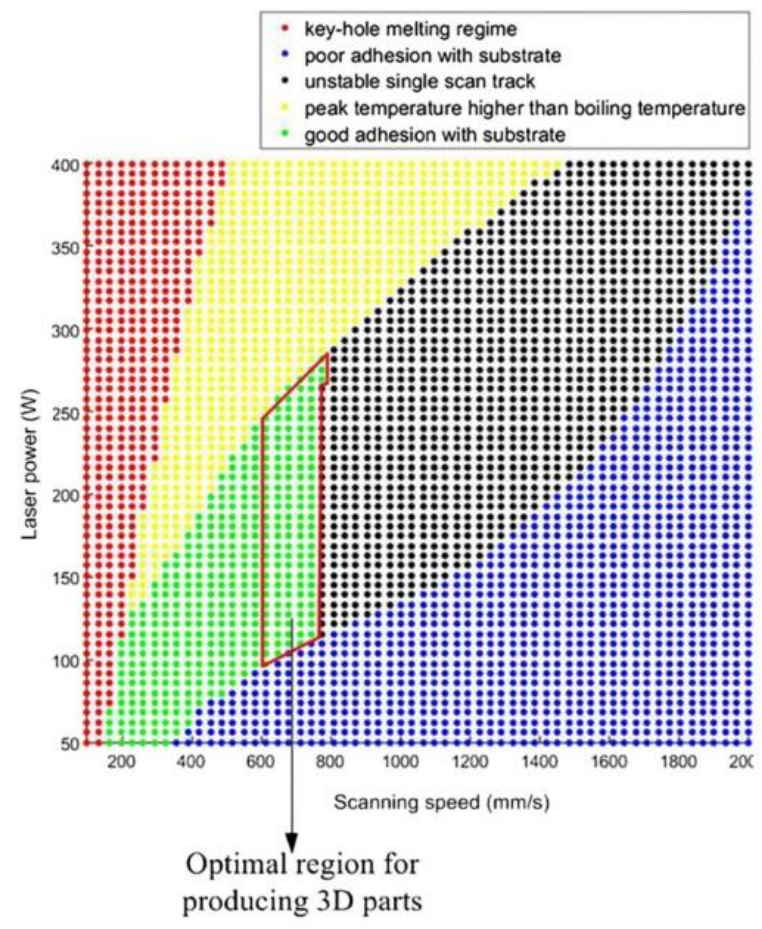

Figure 1. Process map of simulated parameter settings for 316L stainless steel utilizing constraints (Tran \& Lo, 2019).

As seen in Figure 1, the 316L stainless steel (SS) material has a specific window that is simulated to produce near the maximum density (shown in green), and slight changes to the process parameters can result in defects or less dense parts (non-green colors). This relationship can be used to help determine process parameters for optimal surface roughness or mechanical properties.

As most parts will not be solid blocks but have areas of curved surfaces or complex surfaces, several experiments and analyses has been conducted on different materials to investigate the effects of varying overhang structures. One such study ( $\mathrm{Ni}, \mathrm{Shi}, \& \mathrm{Liu})$, examined the effects of incline angles, between $0^{\circ}$ and $90^{\circ}$ from the build plate surface, on surface roughness and corrosion properties for 316L SS. Specifically looking at surface roughness, this research found that increasing the incline angle caused surface roughness. For all the angles tested, the process parameters were constant, allowing the focus to be on the effect of incline angle. Figure 2 shows the average roughness $(R a)$ measurement along the top surface in two directions, parallel and perpendicular to the scan layer. To maintain a constant nomenclature the inclination angles used in this publication would align with the top surface values for the degrees listed, becoming $180^{\circ}$, $150^{\circ}, 135^{\circ}, 120^{\circ}$, and $90^{\circ}$. 


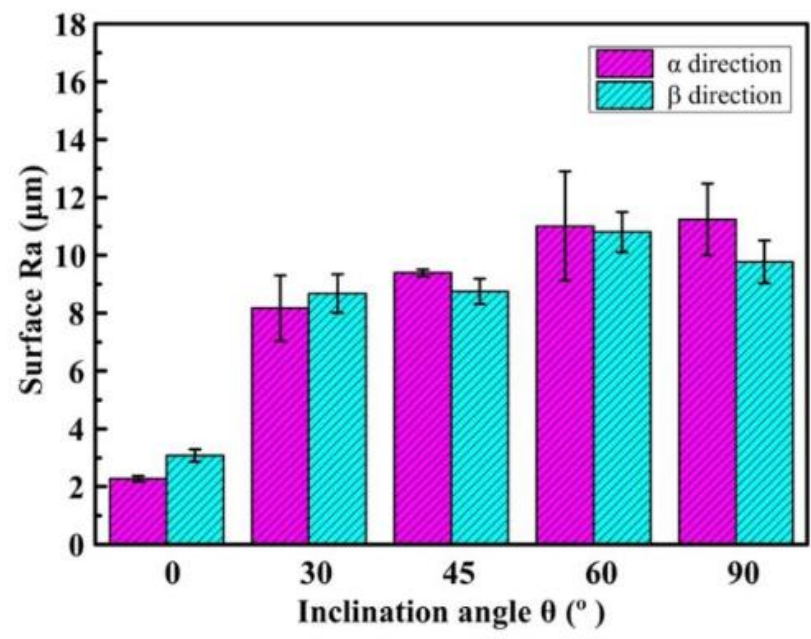

Figure 2. Average surface roughness $(R a)$ of the incline angles' top surface parallel $(\beta)$ and perpendicular ( $\alpha$ ) to the scan direction for 316L stainless steel (Ni et al., 2019).

Shi, Wang, Liu, and Han (2019) also examined 316L SS overhangs, going a step further examining a chrome nickel alloy. The layer thickness varied between the two materials along with the incline angles between $15^{\circ}-75^{\circ}$. Both materials followed the same trend as Figure 2, with surface roughness increasing as the incline becomes closer to parallel with the build plate. Klingaa, Dahmen, Baier, Mohanty, and Hattel (2020) examined the surface roughness of interior cooling channels fabricated in 17-4PH SS. In terms of application, having a smooth inner channel is important to maintain proper flow through the part, and because these interior channels cannot be easily subjected to post-fabrication surface processing. The circular channels were set at seven different inclination angles from $0^{\circ}-90^{\circ}$ at constant exposure settings and a regression model was created to predict the $R a$ for each angle. Once again, this experiment demonstrated there is a strong dependence of surface roughness on inclination angle. It was also noted that the point of each channel with the highest $R a$ value was the top of the circle, which was expected as it is the highest unsupported point of the channel.

Reactive materials such as titanium and aluminum also have the surface roughness and incline angle trend shown by the non-reactive materials such as 316L SS, 17-4PH, and chrome-nickel alloy. Between the reactive and non-reactive metals there should be differences in the values of surface roughness as each material has an optimal parameter set. If the same settings were used for both material types, there would be 
differences in the resulting surface roughness due to the effectiveness of the parameter set melting and fusing the material.

Taking a slightly different approach, Subbaian Kaliamoorthy, Subbiah, Bensingh, Kader, and Nayak (2020) included support structures in their analysis. Utilizing AlSi10Mg with varying exposure settings, it was found that the surface farthest from the front of the machine and perpendicular to the recoater (back surface) had a lower surface roughness value than the front surface due to the presence of overhangs and supports. Figure 3 shows a schematic of the benchmark part with face nomenclature, with the front surface parallel to the recoater blade, away from the dispenser.
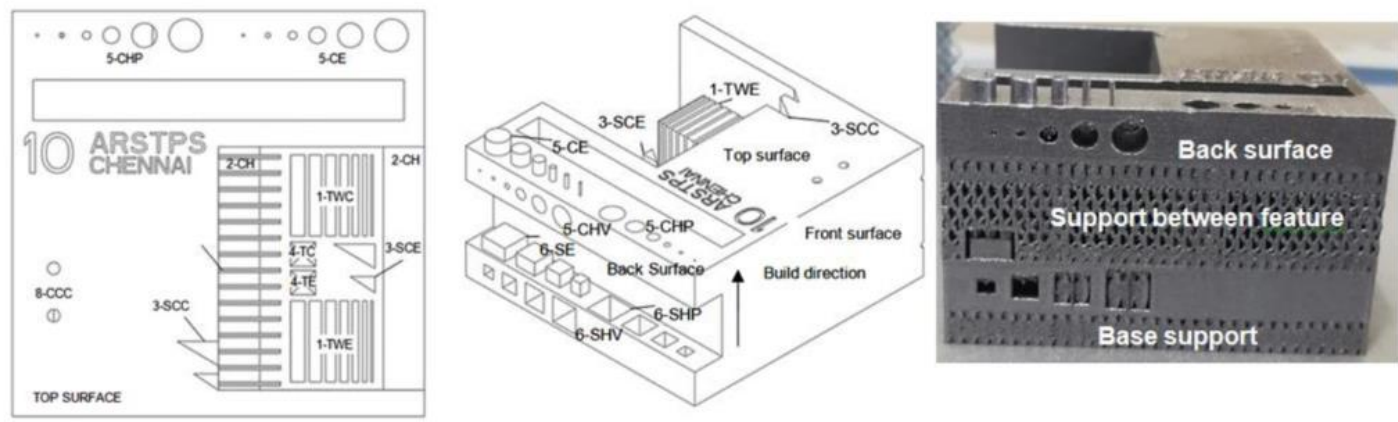

Figure 3. Geometry and surface notation of fabricated benchmark part (Subbaian Kaliamoorthy et al., 2020).

When discussing the surface roughness of the produced benchmark part, the $R a$ value was higher for the front surface followed by the top surface. The values of the $R a$, the average maximum roughness peak $(R z)$, and the root mean square height $(S q)$ are shown in Figure 4Error! Reference source not found..

\begin{tabular}{lccr}
\hline Taylor Hobson profilometer & $\mathbf{R}_{\mathbf{a}}[\mu \mathrm{m}]$ & $\mathbf{R}_{\mathbf{z}}[\mu \mathrm{m}]$ & $\mathrm{Sq}[\mu \mathrm{m}]$ \\
\hline Surface & & & \\
Front & 0.9045 & 3.6456 & 7.7698 \\
Back & 0.3824 & 1.9212 & 6.9743 \\
Top & 0.4879 & 2.2114 & 15.4683 \\
\hline
\end{tabular}

Figure 4. Surface Roughness measurements for benchmark part in terms of surface plane (Subbaian Kaliamoorthy et al., 2020)

The reason for the back surface having the lowest roughness measurements was due to the plane features being supported, which minimized the fusion of un-sintered powder to the features. This analysis 
demonstrated that surface roughness variation can occur for different geometries. Each of these experiments concluded with the same results, increasing incline angles towards $0^{\circ}$ horizontal will increases surface roughness. This relationship is independent of material used as surface roughness values increased for low incline angles in four different materials.

The statement that surface roughness values increase as an incline angle decreases is further supported by research completed by Fox, Moylan, and Lane (2016). In this analysis the relationship between surface roughness and an overhang geometry for 17-4 SS was evaluated using varying laser power and scan speed. What was found is a dependence of the $R a$ value on the overhanging angle. As the angle decreased to $30^{\circ}$, the $R a$ value increased for all contour laser power and scan speed settings, shown in Figure 5. A relationship between incline angle and $R a$ is clear, but another occurrence to not is how each contour set results in a larger $R a$ measurement range as the incline angle decreases to $30^{\circ}$.

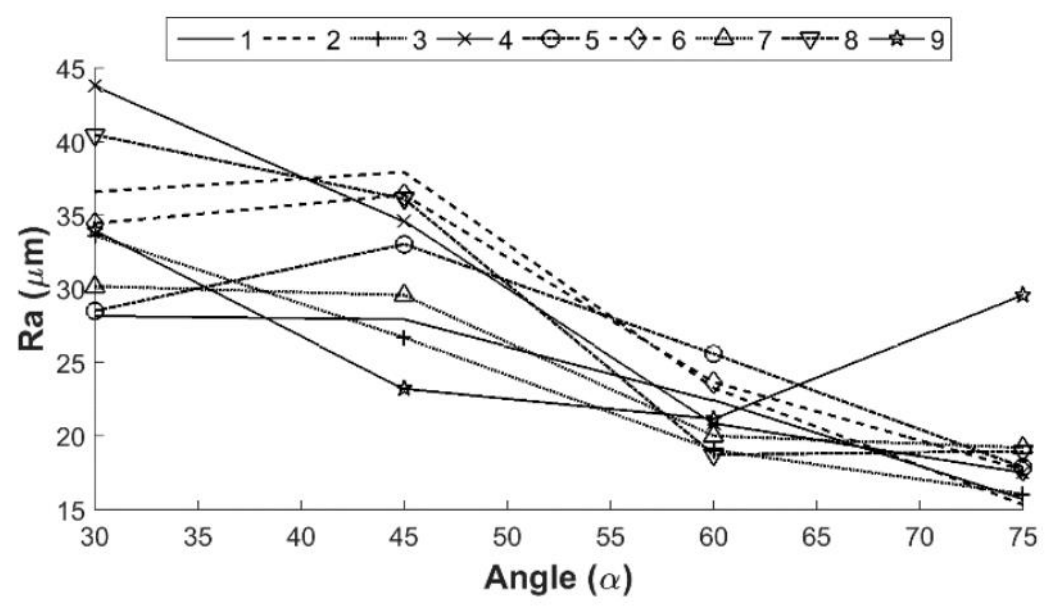

Figure 5. $R a$ of overhang angles $30^{\circ}, 45^{\circ}, 60^{\circ}$, and $75^{\circ}$. (Fox et al., 2016)

\section{EFFECTS OF VARYING SCAN PATTERN STRATEGIES}

The pattern in which a layer is scanned is important to the mechanical properties. Three types of strategies appear throughout several published papers and are bi-directional $/$ meander, chess, and $67^{\circ}$ rotational stripe. DePond et al. (2018) examined these three strategies utilizing solid cubes and hollow cubes to evaluate geometry, fabricated out of $316 \mathrm{~L} \mathrm{SS}$. The goal was to examine how the scan strategies effect the surface quality using height maps of the scanned layer. This paper held constant parameter values for laser 
power, scan speed, and hatch to focus on the effects of the scan path. Figure 6 shows a height map for the bi-directional and $67^{\circ}$ rotational stripe strategies on the solid cube and the strategy path while Figure 7 shows the difference in surface roughness for the two strategies on a layer base.

a)

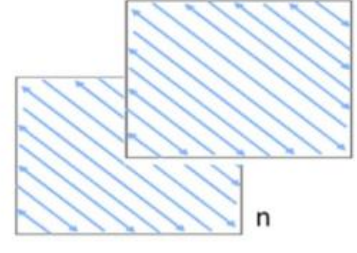

b)

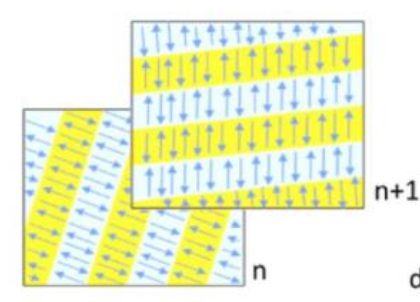

c)

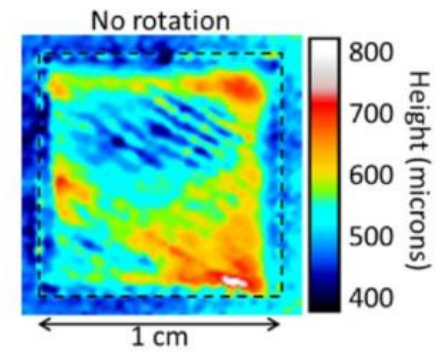

d)

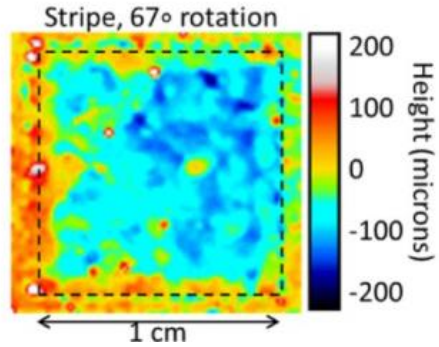

Figure 6. a) Path lines for bi-directional scan. b) path line for a $67^{\circ}$ rotational stripe. c) height map for no rotation, bi-directional scan and d) height map for stripe path with rotation (DePond et al., 2018).

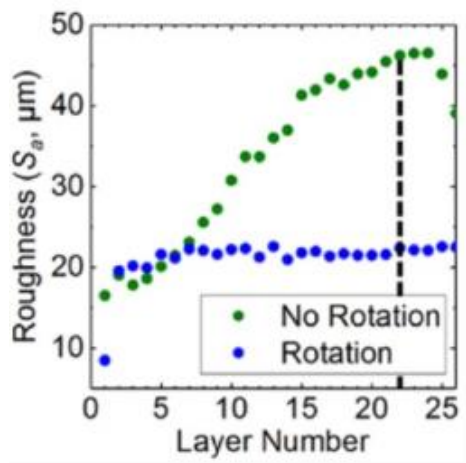

Figure 7. Surface roughness values, taken at each layer, with and without a $67^{\circ}$ rotational stripe (DePond et al., 2018).

In Figure 6 there is a black dotted outline for (c) and (d), that show the dimension of the cube. The bi-directional or no rotation scan has larger height deviations than the $67^{\circ}$ rotated strategy which ties into the conclusion for surface roughness and helps confirm the trend shown in Figure 7. By rotating the scan path $67^{\circ}$ between each layer, surface roughness is reduced and held close to $20 \mu \mathrm{m}$. 
A prior study conducted by Shi et al. (2019) discussed geometry analysis. This same study also examined the chess, meander, and $67^{\circ}$ rotational stripe scan strategies for their blocks fabricated in 316L SS and a chrome-nickel alloy. What was found was that the chess and meander strategies produced low surface roughness for the chrome-nickel alloy while the stripe produced low surface roughness for $316 \mathrm{~L}$ SS. The chess pattern is suitable for incline angles near perpendicular to the build plate. Meander and stripe are suitable for incline angles closer to parallel with the build plate. Overall, the scan strategy can affect the surface roughness and optimal strategies can differ between materials.

\section{EFFECTS OF VARYING EXPOSURE SETTINGS ON SURFACE ROUGHNESS}

The exposure variables include laser power, scan speed, and hatch distance, each having their own relationship with surface roughness. These settings can be used to create exposure strategies such as fill, upskin, downskin, and contour. Figure 8 demonstrates the naming nomenclature for surfaces at an incline, along with where each strategy is activated for a given layer slice for the overhang geometry.

DePond et al. (2018) adjusted the top surface or up-skin laser power to surface roughness changes. This paper also utilized a different measurement method called spectral domain optical coherence tomography (SD-OCT). The SD-OCT collects surface topography through reflected light off the scanned layer. Figure 9 shows the changes in surface roughness when altering the up-skin laser power. 


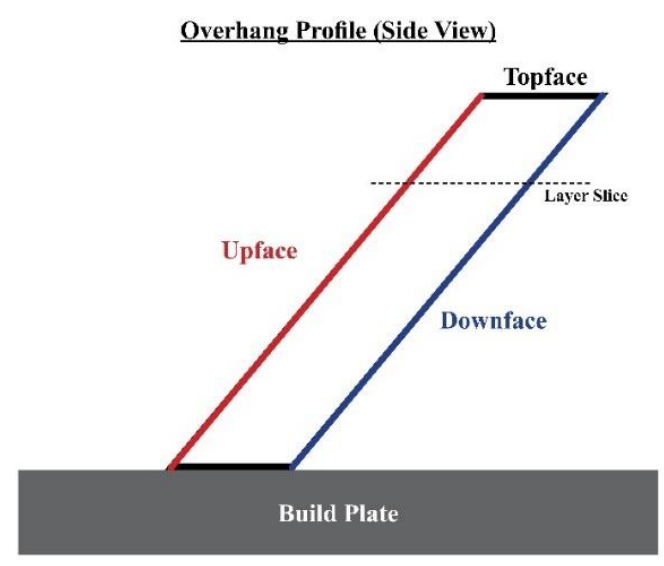

Overhang Laver Slice (Top View)

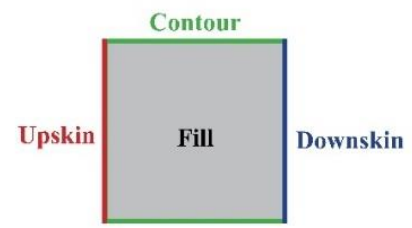

Figure 8. Overhang part surface nomenclature and layer slice denoting the activation areas of different exposure settings.

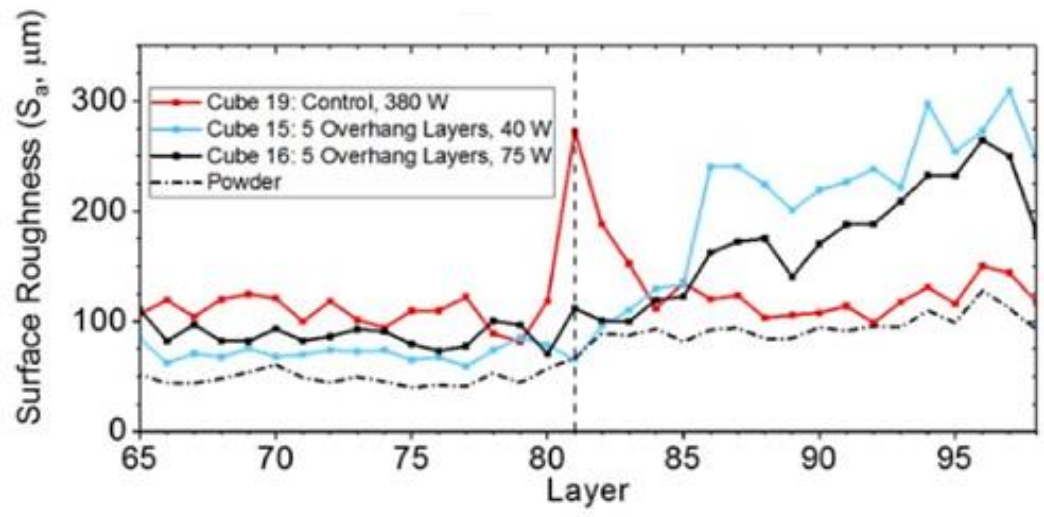

Figure 9. Arithmetical mean height ( $\mathrm{Sa}$ ) of top surface of hollow cube with different laser powers for upskin and downskin on overhang layers (DePond et al., 2018).

Increasing the laser power of the top surface results in re-melting the top several layers based on the input energy. The trend shown in Figure 9 shows that increasing the upskin laser power increases the surface roughness. Shi et al. (2019) found similar results adding that increasing the number of scans will decrease roughness, as the layers are re-melted.

Deng, Mao, Yang, Niu, and Lu (2020) utilized a design of experiments software to determine the optimization of laser power, scan speed, and hatch distance of 316L SS. Building samples in a range of exposure settings, it was clear that laser power had a significant effect on surface morphology as shown in 
Figure 10. Unlike laser power and scan speed, the hatch distance did not have a significant effect on surface roughness. Tran and Lo (2019) confirmed the strong relationship between surface roughness, laser power, and scan speed through their finite element analysis and artificial neural network analysis of over 3600 combinations of exposure parameters. The analysis concluded that a low scan speed increased surface roughness and for the 316L SS material, and process map shown in Figure 1, where the optimal surface roughness and density range is outlined. Since the main objective of the paper was to maximize density, there is reason to believe that the optimized parameters selected in Figure $\mathbf{1}$ can be altered if the focus was on surface roughness.
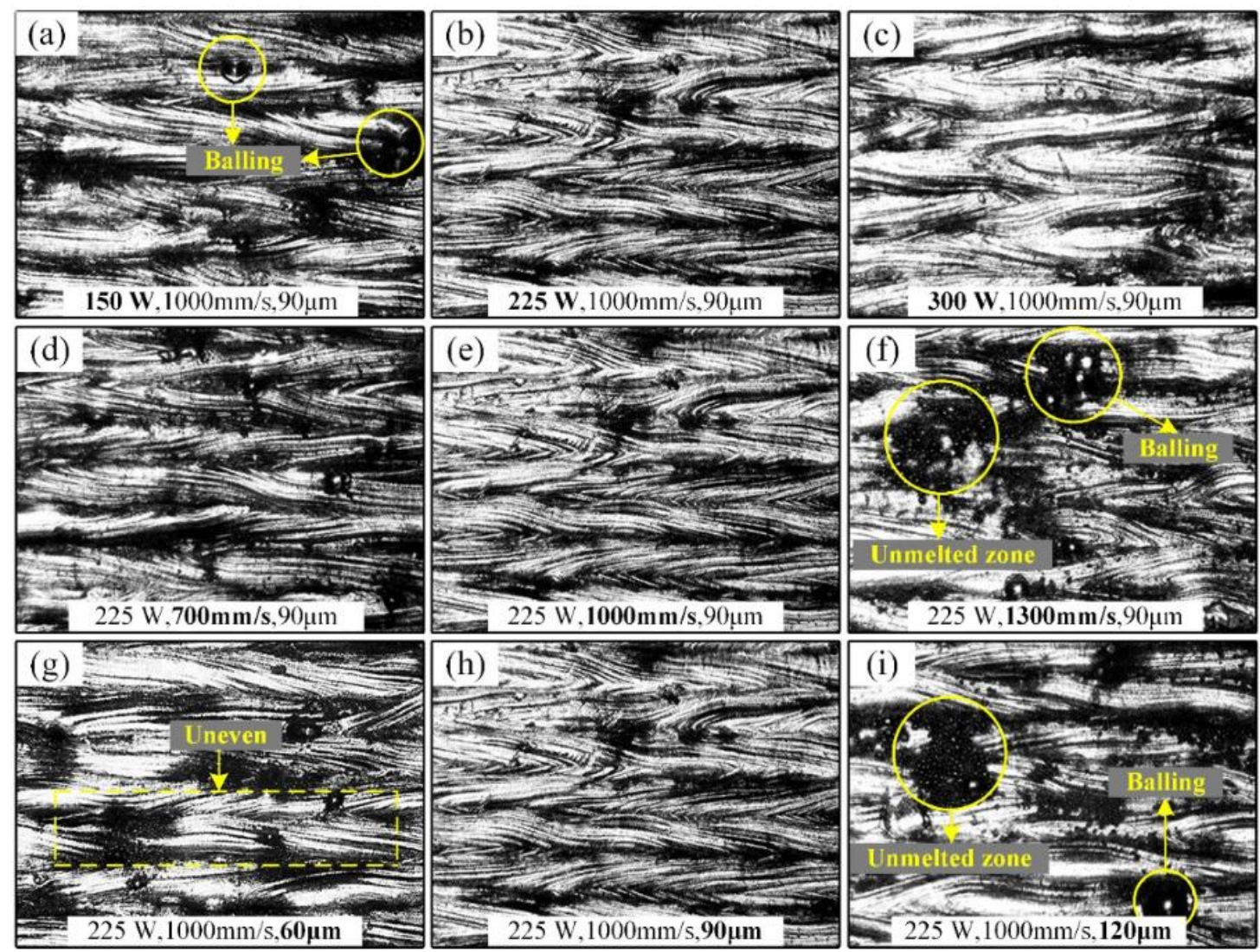

Figure 10. Surface morphology of parts built at varying laser power, scan speed, and hatch distance (Deng et al., 2020).

Referring to the work mentioned in SURFACE ROUGHNESS, authors Fox et al. (2016) found a relationship between the part geometry and surface roughness, however another scope of the work was to determine a connection between surface roughness and the contour parameters. After analyzing the data, the 
authors cited that a clear connection between the $R a$ and the parameters could not be found with the angled blocks fabricated, calling for a feature based part to examine the connection.

\section{DIMENSIONALITY}

Dimensionality as the focus of research is limited in published work. Instead dimensional accuracy is a supporting subject used to help well-round experimental analysis. The National Institute of Science and Technology (NIST), while organizing and determining how to control variability in part quality, gathered the few published work to discuss what inputs affect the dimensional outcome of parts (Mani, Lane, Donmez, Feng, \& Moylan, 2017). Dimensional accuracy and tolerance are not the focus of the review, but the knowledge presented supports the scope of controlling part quality for powder bed fusion part fabrication.

Within the review it was stated that process parameters were the "inputs" that are the main factor in the amount of energy that is sent to the powder and the resulting interaction. From that statement manipulations to the process parameters will affect the resulting part, what the specific results are determined by experimental analysis. The review included the work completed by Delgado, Ciurana, and Rodríguez (2012) on dimensionality of metal parts. The results concluded that the build direction can affect the dimensional accuracy of parts. The review also included the work by Wang, Yang, Yi, and Su (2013) that specifically examined the quality of overhanging surfaces, finding that control over a part orientation and the energy input into the material will affect the quality. Better control and optimization with improve quality of overhanging surfaces.

The work completed by Calignano, Peverini, Addamo, and Iuliano (2020), while not cited in the NIST review due to publication time, demonstrated the effect of reducing the radius of an internal channel. Utilizing a constant core and contour parameter setting, denoting the values assigned for upskin and downskin laser power and scan speed, the authors found that as the radius decreased from $50 \mathrm{~mm}$ to $30 \mathrm{~mm}$, deviations did as well. The deviations were averaged across the twisted internal channels. The measured values were verified through calculations determining the deviations to not be a result of layer lines. In their conclusion Calignano, Peverini, Addamo, and Iuliano (2020) cited that a compensated CAD should be used to accuratedly fabricate parts after an optimized parameter set has been created. 


\section{EXPERIMENTAL SETUP}

\section{BENCHMARK PART}

A single part was designed to include all tested geometries to limit the number of parts to fabricate.

Two versions of the benchmark part were used. The first version, v1, had solid overhang bars for $30^{\circ}, 45^{\circ}$, $60^{\circ}, 75^{\circ}$, and $90^{\circ}$. The final version, v2, was larger in overall size to ensure adequate surface area for testing the surface roughness and included three feature sizes to measure convex and concave radii. The two different geometries are shown in Figure 11 with their overall dimensions shown in Table 1.

(a)

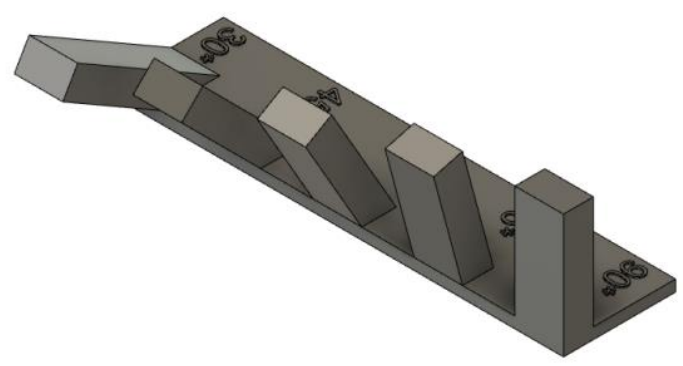

(b)

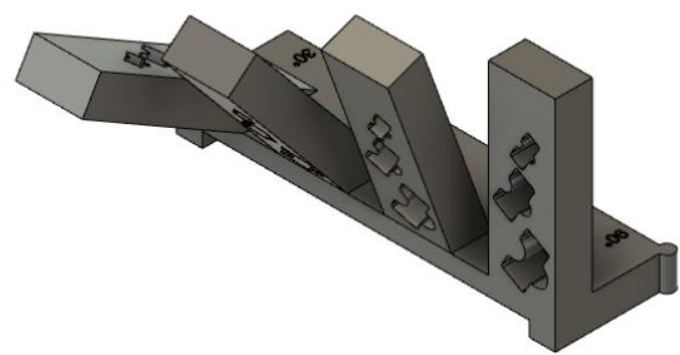

Figure 11. Benchmark geometry of (a) v1 and (b) final version, v2.

Table 1. Benchmark Part dimensions

\begin{tabular}{|c|c|c|c|c|}
\hline Version & $\begin{array}{c}\text { Overall Dimension } \\
(\mathrm{mm})\end{array}$ & Overhang Values & $\begin{array}{c}\text { Overhang 'Block' } \\
\text { Dimension }(\mathrm{mm})\end{array}$ & Hole radii $(\mathrm{mm})$ \\
\hline 1 & $60.5 \times 15 \times 17$ & $30^{\circ}, 45^{\circ}, 60^{\circ}, 75^{\circ}, 90^{\circ}$ & $15 \times 4 \times 6.5$ & - \\
\hline 2 & $102 \times 30 \times 55$ & $30^{\circ}, 50^{\circ}, 70^{\circ}, 90^{\circ}$ & $50 \times 10 \times 18$ & $1,2,3$ \\
\hline
\end{tabular}




\section{MACHINE SETUP}

An EOS M290 Direct Metal Laser Sintering (DMLS) machine was utilized for all part fabrication. A ceramic rigid recoater blade was used for all testing, and the material was 17-4 SS. Initial testing with version 1 of the benchmark part was completed for contour sets 1 and 2 to examine the effect of beam offset. The final test geometry was built for contour sets 2-5. Both parts were fabricated with a constant fill parameter set and strategy pattern. Only the beam offset, laser powers, and scan speeds were adjusted for the different contour parameter sets. All tested values for each variable are shown in Table 2. A single contour line was utilized with the laser completing two passes along this line. If two contour lines were utilized then a beam offset could be assigned to each line. The upskin laser power and scan speed are activated when an area of the layer will not be scanned on the next layer. The downskin settings are activated for the opposite when the area below the current section was not scanned. This event is expressed graphically by Figure 8 .

Table 2. Parameter values

\begin{tabular}{|c|c|c|c|c|c|c|c|}
\hline \multirow{2}{*}{ Set No. } & \multicolumn{3}{|c|}{ Laser Power (W) } & \multicolumn{3}{c|}{ Scan Speed (mm/s) } & \multirow{2}{*}{$\begin{array}{c}\text { Beam Offset (mm) } \\
\text { [line 1, line 2] }\end{array}$} \\
\cline { 2 - 7 } & Standard & Upskin & Downskin & Standard & Upskin & Downskin & $0.02,0$ \\
\hline 1 & 60 & 60 & 40 & 700 & 700 & 700 & $0.1,0.08$ \\
\hline 2 & 60 & 60 & 40 & 700 & 700 & 700 & $0.1,0.08$ \\
\hline 3 & 120 & 120 & 120 & 700 & 700 & 700 & $0.1,0.08$ \\
\hline 4 & 60 & 60 & 40 & 350 & 350 & 350 & $0.1,0.08$ \\
\hline 5 & 120 & 120 & 120 & 1400 & 1400 & 1400 & \\
\hline
\end{tabular}

\section{QUANTITATIVE ANALYSIS}

\section{SURFACE ROUGHNESS}

A Mitutoyo SJ-210 surface profilometer was used to measure the surface roughness of the specimen for both planes and holes. A $0.75 \mathrm{mN}$, diamond tip gauge detector was used for all measurements. The stylus profile includes a tip radius of $2 \mu \mathrm{m}$ and tip angle of $60^{\circ}$. A custom apparatus was created to hold the profilometer along the measured surfaces to ensure repeatability. The profilometer was held perpendicular to the measure surface for the duration of each measurement, but the "caps" ensured the profilometer was perpendicular to the surface and would not move once testing began. 
Data was recorded and output into a certificate presentation using Surftest, the software created by Mitutoyo for surface profilometer testing.

Table 3 shows the constant setting in which all surface roughness measurements were taken at, including the filter, cutoff length (Lc), and sample length (Ls).

Table 3. Surface Profilometer settings

\begin{tabular}{|l|l|}
\hline Standard & ISO1997 \\
\hline Profile & R \\
\hline Filter & Gauss \\
\hline Ls & $2.5 \mu \mathrm{m}$ \\
\hline Lc & $0.8 \mu \mathrm{m}$ \\
\hline N & 8 \\
\hline
\end{tabular}

A specific nomenclature was used to quantitatively classify the upface, downface, and topface surfaces for analysis, specifically for surface roughness. The assigned incline angle was determined based upon the direction of the surface measurements were taken. A visual for surface angles is shown in Figure $\mathbf{1 2}$ and Table 4 shows how the surface angles are classified in this analysis.

Table 4. Nomenclature for surface angle based upon surface location and overhanging bar incline angle.

\begin{tabular}{|c|c|c|c|}
\hline Overhang Bar & Upface & Downface & Topface \\
\hline 90 & $90^{\circ}$ & $90^{\circ}$ & $180^{\circ}$ \\
\hline 70 & $120^{\circ}$ & $70^{\circ}$ & $160^{\circ}$ \\
\hline 50 & $150^{\circ}$ & $50^{\circ}$ & $140^{\circ}$ \\
\hline 30 & $180^{\circ}$ & $30^{\circ}$ & $120^{\circ}$ \\
\hline
\end{tabular}




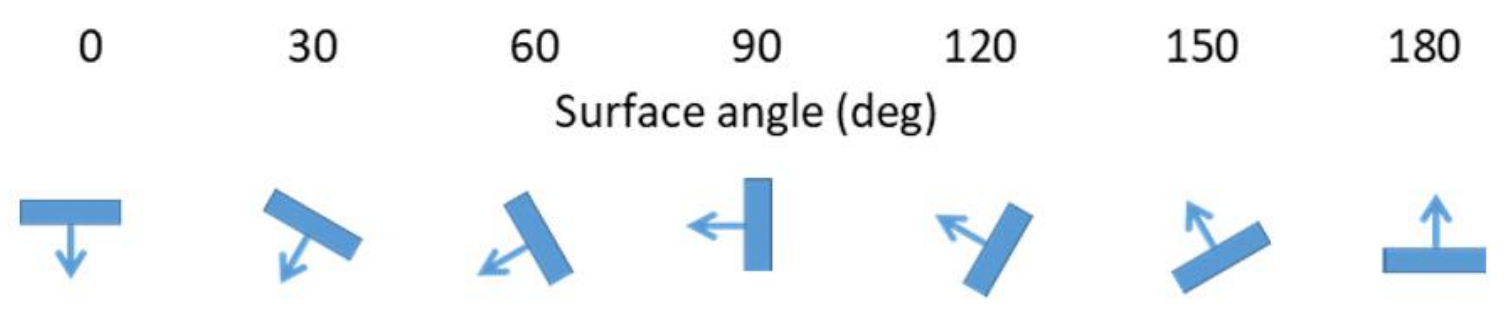

Figure 12. Standard nomenclature for part surfaces based on the incline angle from the build plate top surface.

The hole features were labelled differently as two types of surfaces were generated, concave and convex, each at three different radii. A total of four measurement location were established for each surface type that correlates to the surface measurement nomenclature shown in Figure 12. The general measurement area for the hole features are shown in Figure 13.

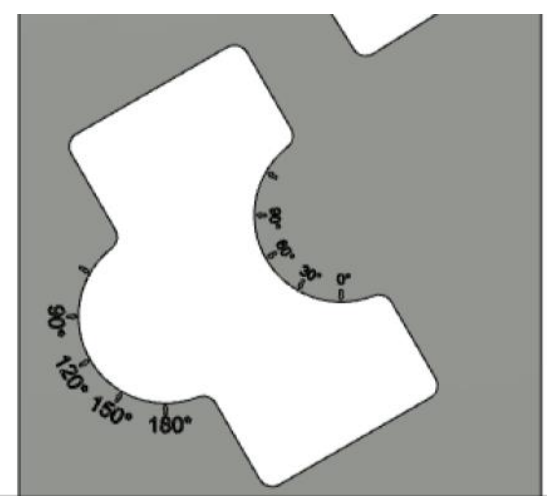

Figure 13. Measurement locations for concave and convex hole features on each overhanging bar, denoted in the surface angle nomenclature presented in Figure 12.

\section{DIMENSIONALITY}

To measure the dimensionality of the as-built samples a CMM was programed. Utilizing a Renishaw PH10T probe with a $1 \mathrm{~mm}$ diameter ruby tip on a Brown \& Sharpe One CMM, a program was designed in Nikon CMM-Manager Software. The program included measurements of the thickness and width of each overhang bar, and the radius of each hole created through the bars. A report for each bar was output at the end of the program to denote the measured values and the deviation from CAD values. The dimensionality was tested to examine the effects of adjusting the contour laser power, scan speed, and beam offset values. 
The beam offset was examined through measuring the $\mathrm{v} 1$ overhang specimen, and the laser power and scan speed were examined with the v2 specimen.

Due to the research timeline, the v1 overhang specimen was measured with digital calipers, which take the measurement of highest peak to highest peak. The CMM measurements are point based with a round probe tip, resulting in the potential for measurements to be made on a peak or valley on the part surface. A difference in tolerance from each measurement method should be noted with claimed accuracy of the CMM to be 1 micron or $0.001 \mu \mathrm{m}$ while it is unreasonable to claim accuracy that small for a digital caliper. Since the beam offset settings of the $\mathrm{v} 1$ benchmark part is to examine the overall dimensions of each bar to compare to the $\mathrm{CAD}$, the digital caliper results are adequate. However, any attempts to compare the results of the v1 and v2 benchmark parts will need to maintain knowledge of the two different tools used to measure the part dimensions. 
RESULTS

\section{DIMENSIONALITY}

\section{EFFECT OF VARIATION IN LASER POWER AND SCAN SPEED}

The CMM program allowed for the thickness and width of each overhanging bar to be measured. In terms of the measured surface and inclination angle there is a correlation between the incline angle and the thickness CAD deviation. Figure 14 shows the measured thickness and width of each incline bar for contour sets 2-5. Each contour set is denoted by their laser power (W) and scan speed $(\mathrm{mm} / \mathrm{s})$ settings and the CAD or nominal value is denoted. The thickness is measured as the difference between the upface and downface, while the width is the cross-section between the two planes.

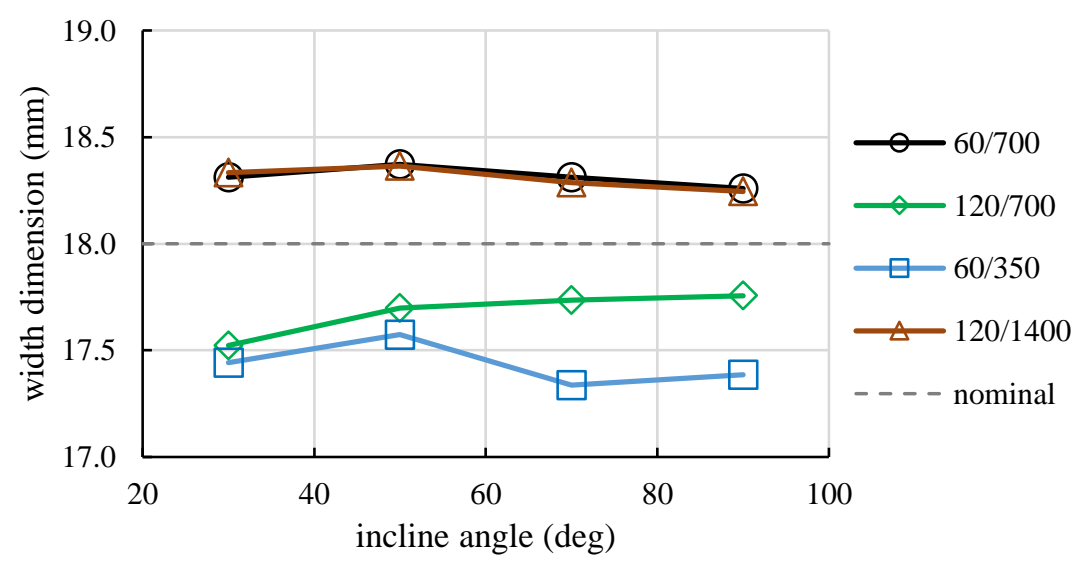




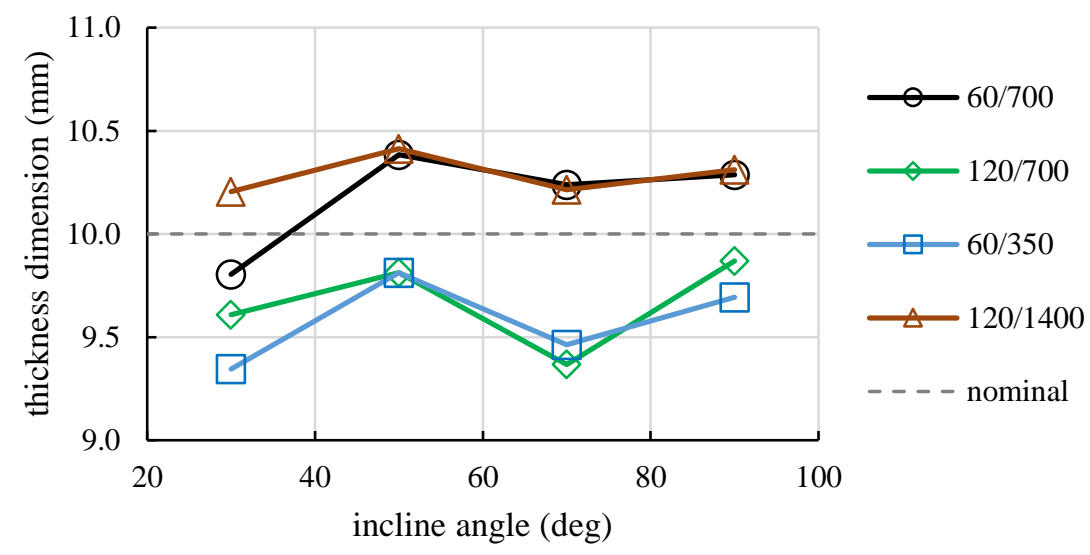

Figure 14. (a) measured width and (b) measured thickness of the v2 overhanging bar for varying laser power and scan speed settings correlating to contour sets 2 through 5 .

From the data a clear separation is shown between two groups of laser power and scan speed values. This separation can be attributed to energy density values or result from the four samples being split between two builds and the two different energy densities $0.086 \mathrm{~J} / \mathrm{mm}$ (top group) and $0.171 \mathrm{~J} / \mathrm{mm}$ (bottom group). The thickness measurement also demonstrated, specifically for the v2 specimen, that as the incline angle decreases to $30^{\circ}$ that the downskin plane is not flat, and sags as shown in Figure 15. This result occurred for all four v 2 benchmark specimens but was prominent for the contour sets 2 and 5 . There was also discoloration in each sample that looked as if the samples burned which was determined to be a result of the part geometry and lack of heat dissipation during fabrication.

(a)

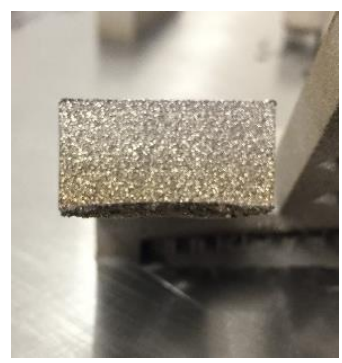

(b)

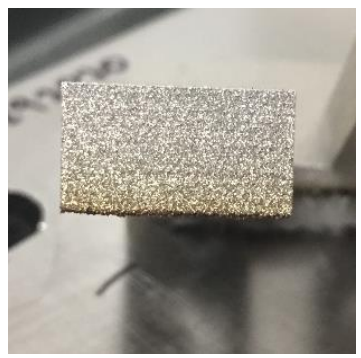

(c)

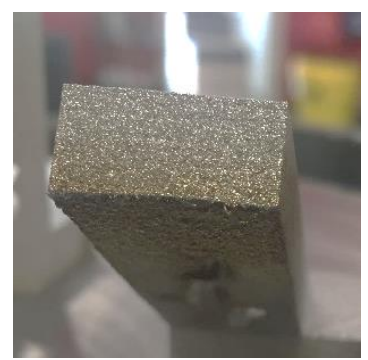

(d)

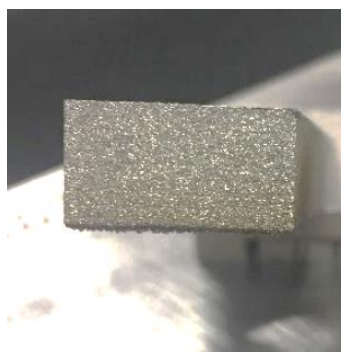

Figure 15. $30^{\circ}$ downskin sagging for (a) contour set 2 (b) set 3, (c) set 4, and (d) set 5 .

The CMM measurements were able to verify that as the incline angle decreases to $30^{\circ}$, downfacing surfaces increase their distance from $0 \mathrm{~mm}$ or flat shown in Figure 16, with a larger sagging effect for some 
of the contour settings. This is also shown through a color gradient point cloud measurement for each overhang bar. Each incline value and the color gradient for each surface is shown in Figure 17. The color gradient is broken up to the cooler colors demonstrate expansion, such as sagging, while the warm colors express contraction. The expansion effect is reversed when the incline angle is increased toward $90^{\circ}$, demonstrated by the shrinkage of the topface, similar to a meniscus shown in Figure 17. This behavior occurs for contour sets 2 through 5 and the reports for each benchmark specimen fabricated are shown in Appendix A (Figure 22-25) along with the flatness report for each contour setting and overhang bar (Table.

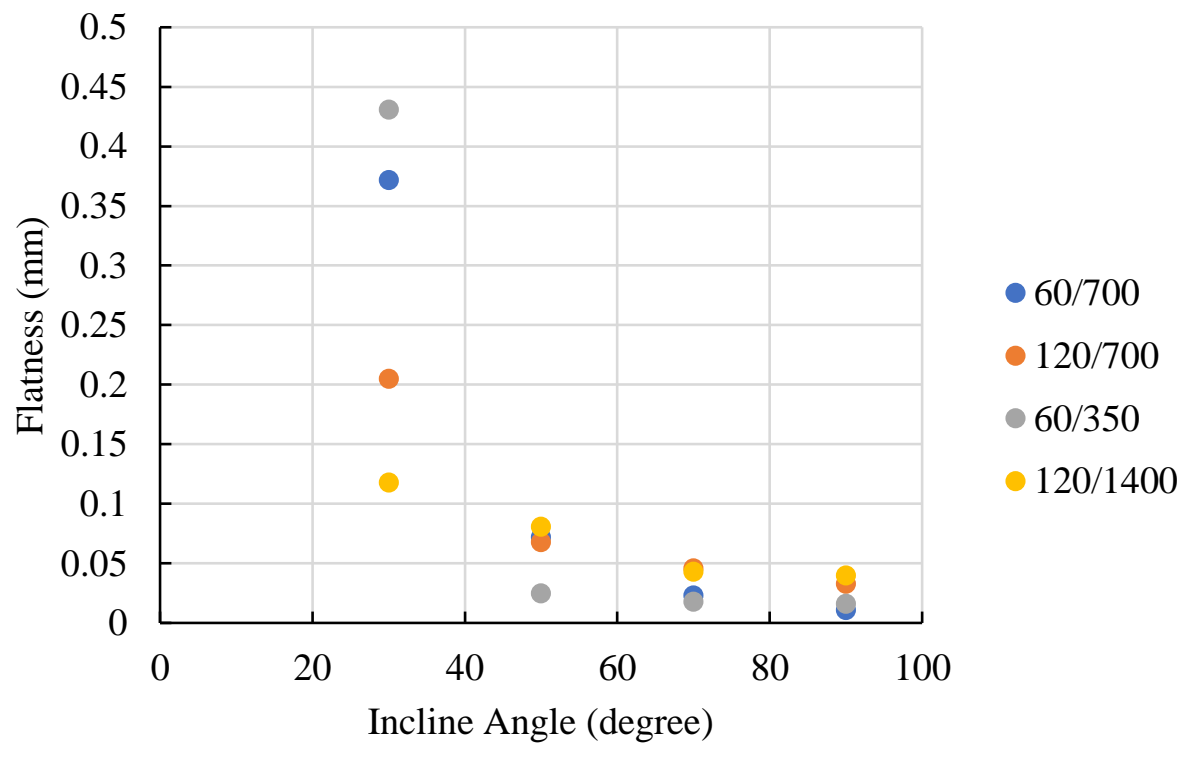

Figure 16. Flatness of the downface surfaces for contour sets 2 through 5 from the CMM program report. 
(a)

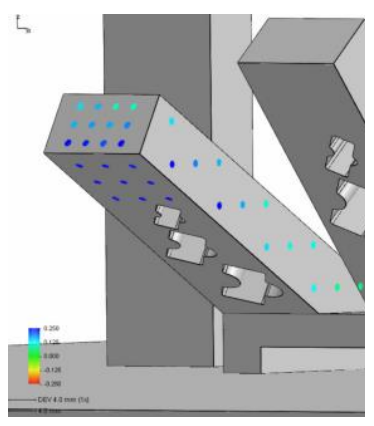

(b)

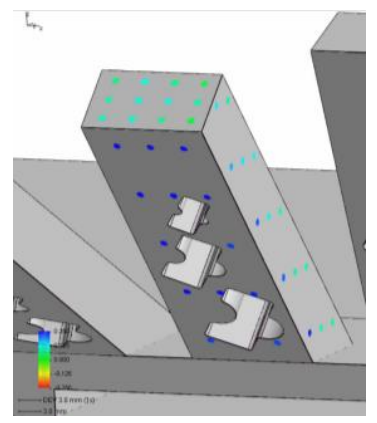

(c)

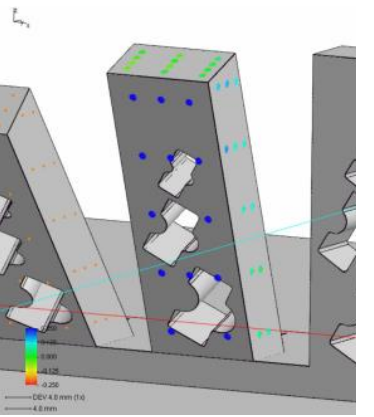

(d)

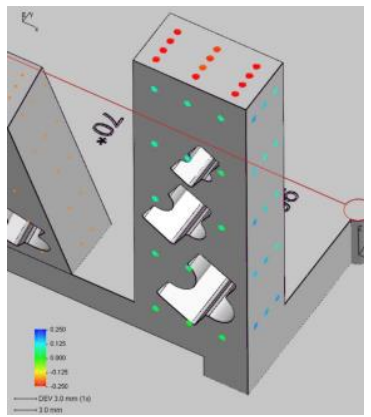

Figure 17. Point cloud color mapping of v2 overhang specimen at (a) $30^{\circ}$, (b) $50^{\circ}$, (c) $70^{\circ}$, and (d) $90^{\circ}$.

There is clear evidence that a relationship exists between the part geometry and the resulting dimensionality of fabricated parts. A connection between the laser power and scan speed also exists with the dimensional accuracy of overhanging surfaces. This evidence is initially shown through the CMM measurements of the thickness and width and verified through the point cloud color gradient and visible inspection.

\section{EFFECT OF VARIATION IN BEAM OFFSET}

A test to examine the effect of the contour beam offset in the dimensionality of the benchmark part was conducted early on with the initial overhang benchmark specimen and contour sets 1 , and 2 . The purpose of the beam offset is to help maintain dimensional accuracy of the supplied STL to the fabricated part. Adjusting the beam offset moves the center of the laser inward or outward from the part's contour. The typical offset value is around the radius of the melt pool diameter so the contour of the part matches with the edge of the melted material. The two beam offset settings each have the potential for two contour passes and the values are denoted as $1^{\text {st }} / 2^{\text {nd }}$. The thickness and width measurement deviations from CAD for the two beam offset settings are shown in Figure 18. 


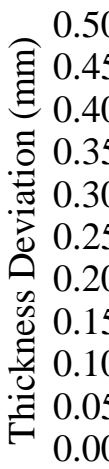

-

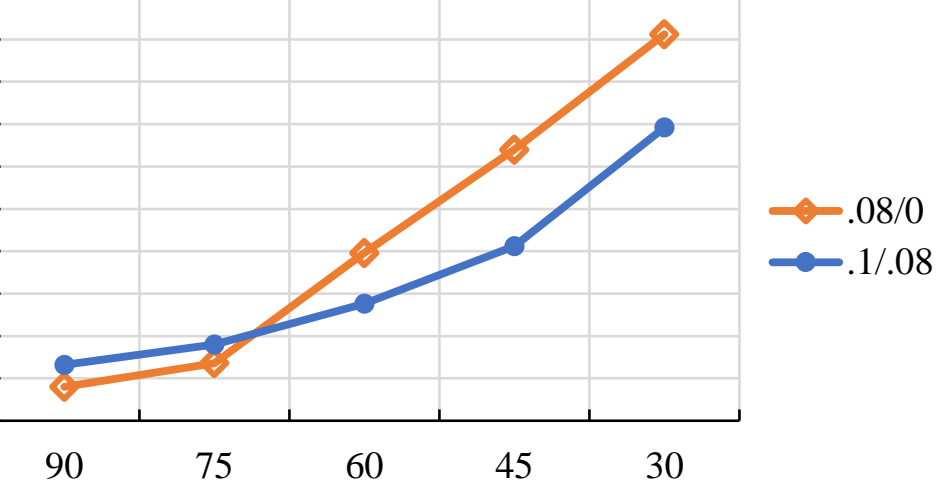

(a)

Overhang Angle (deg)

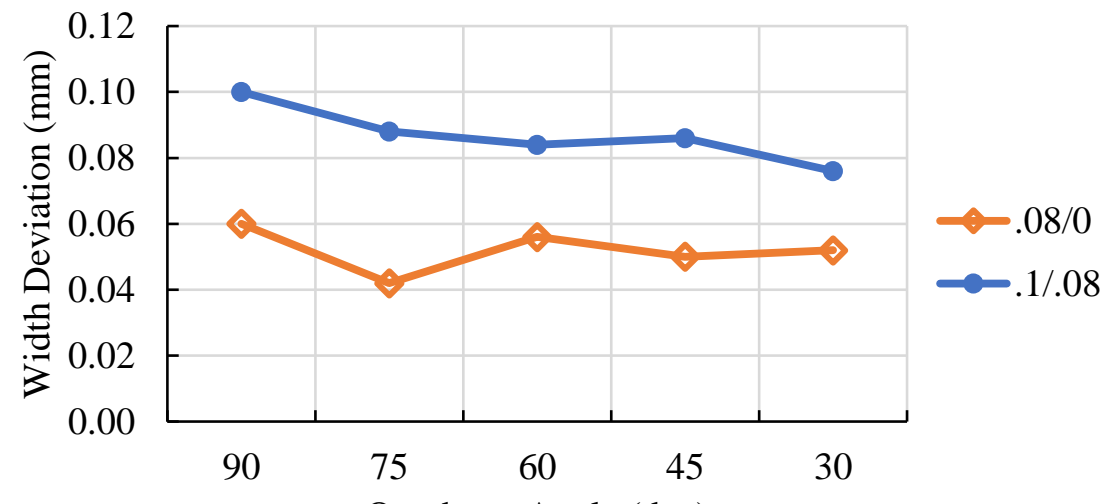

(b)

Overhang Angle (deg)

Figure 18. (a) Thickness and width measurement deviations of v1 specimen for beam offsets of $0.08 / 0$ and $0.1 / 0.08$.

While the effects of increasing the beam offset is clear in the width measurement, the separation of the two beam offset settings is closer in the thickness measurement. The increase in deviation from CAD was expected to occur for the thickness dimension, since the overhang bars were not supported. When comparing the effects of beam offset to the effects of laser power and scan speed, the beam offset changes resulted in a smaller deviation from the nominal feature sizes. 


\section{SURFACE ROUGHNESS}

\section{PLANAR SURFACES}

For the planar surfaces, the surface roughness testing resulted in the same trend occurring for each of the tested contour laser power and scan speed bundles. The presence of a $3^{\text {rd }}$ order polynomial trendline with similar amplitude values confirms the statement that the surface roughness of planar surfaces does not differentiate much between varying contour settings. The main control over surface roughness some from part geometry. Both relationships can be seen in Figure 19. The $30^{\circ}$ downskin was not able to be measured due to the profilometer exceeding its measurable limits and is not shown in the figure. From the presence of the polynomial trendlines it is expected for the $30^{\circ}$ downskin to exceed $40 \mu \mathrm{m} \mathrm{Ra}$.

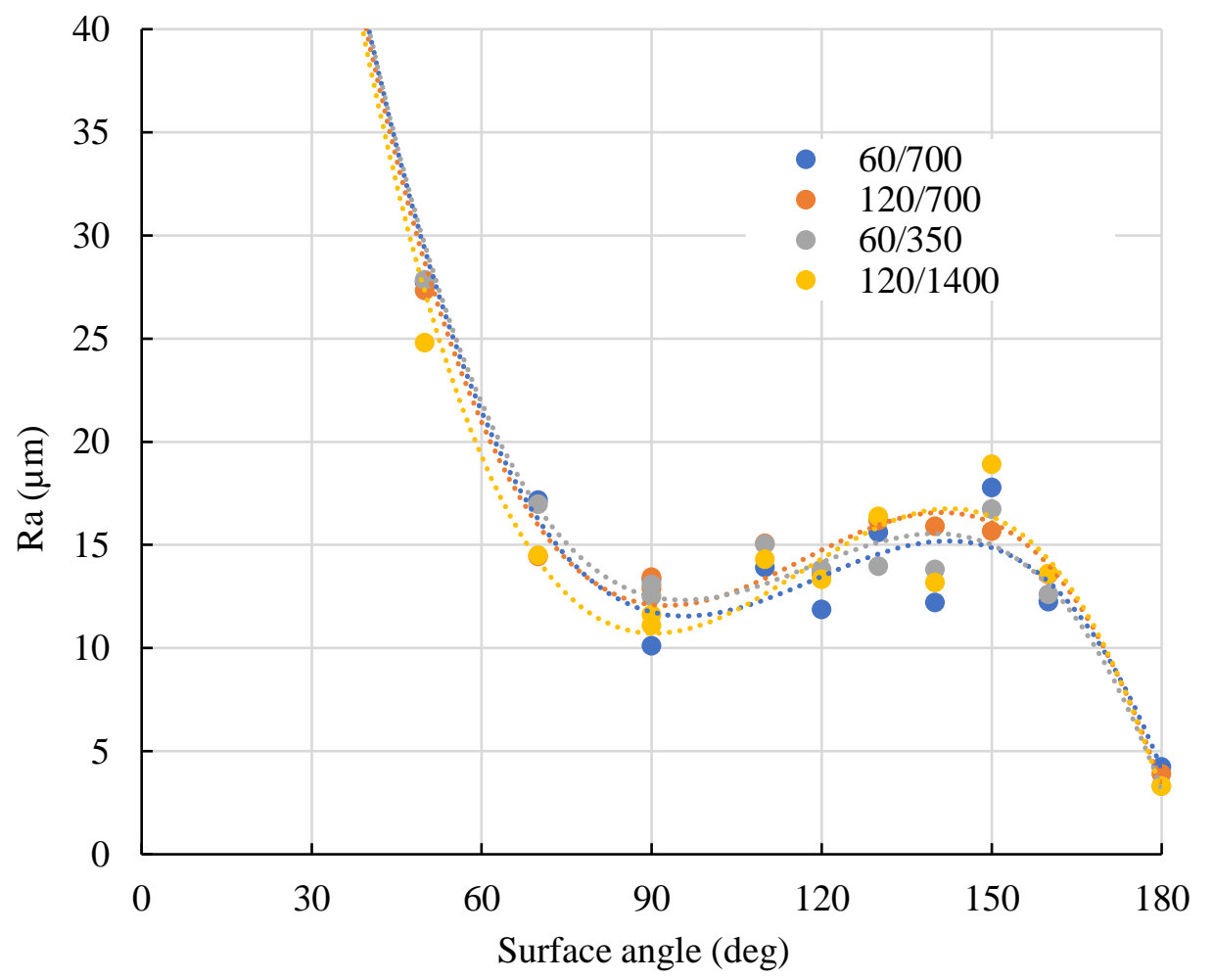

Figure 19. Surface roughness data for upface, downface, and topface surfaces of the v2 overhanging bar across contour sets 2 through 5 . 


\section{CONCAVE AND CONVEX HOLES}

The addition of the concave and convex holes provided insight into how unsupported features are affected by varying the build parameters and their location on an overhanging part. In regard to the varying the laser power and scan speed the surface roughness followed a similar trend across all parameter sets which is shown in Figure 20b for an overhang angle of $50^{\circ}$ and measurement angle of $180^{\circ}$ concave. The surface roughness across each angle was similar, however due to the measurement being of the $180^{\circ}$ concave, the profilometer stylus was located on a section that was parallel to the build plate, resulting in a smaller roughness measurement from the absence of a layer line. Other than the occurrence for the $90^{\circ}$ holes, there is a slight difference for the surface roughness of the holes in terms of incline angle. The $50^{\circ}$ incline had the highest $R a$ values, but it should be noted that the difference between the other incline angles is within $5 \mu \mathrm{m}$. When comparing the different radii, the $1 \mathrm{~mm}$ radius has higher $R a$ values across all incline angles. This is due to the $90^{\circ}$ incline having smaller surface roughness values for the $180^{\circ}$ concave measurement. The surface roughness for all measurement angles, contour settings, and hole size can be found in the Appendix,

\section{Table 8-11.}

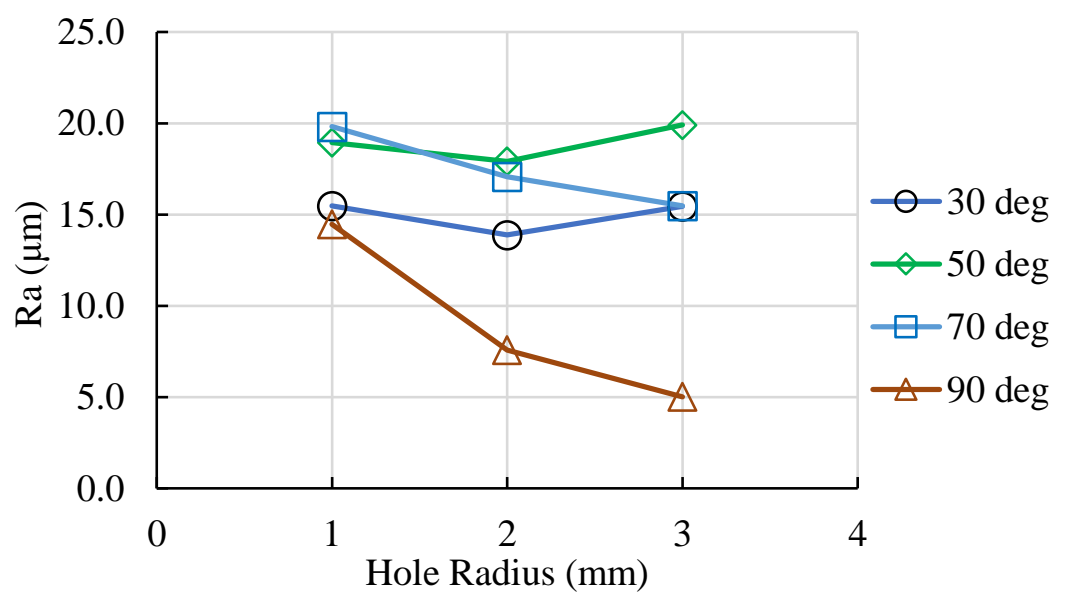




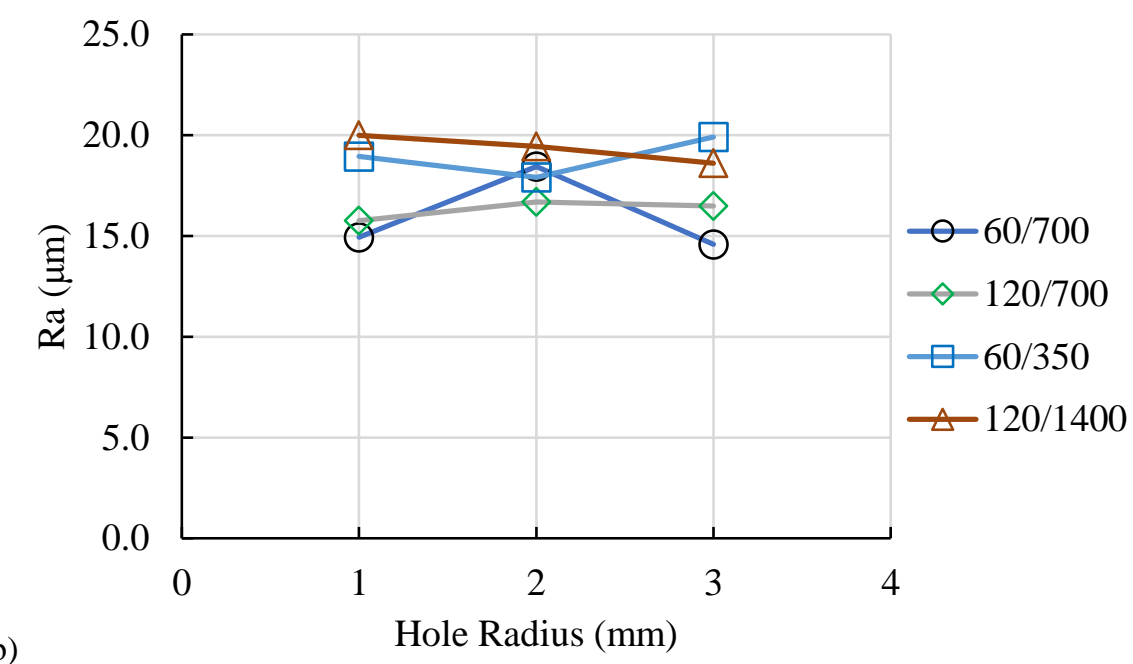

Figure 20. Effect on surface finish for hole features with (a) varying incline angle for a single parameter measured at $180^{\circ}$ concave, and (b) varying parameter for a single incline angle at $50^{\circ}$.

The measurements between the two extremes for concave and convex surfaces follow a similar trend across all tested contour sets. The trend is that the measurements between the $90^{\circ}$ and bottom measurement location have values that fit within the two extremes found at the outside measurement locations. Figure 21 shows these trends for both (a) the concave and (b) convex measurement angles. The middle measurement locations were difficult to measure and therefore are not listed, however they are assumed to follow the same trend as the $\mathrm{r} 2$ and $\mathrm{r} 3$ measurements since the endpoints do.

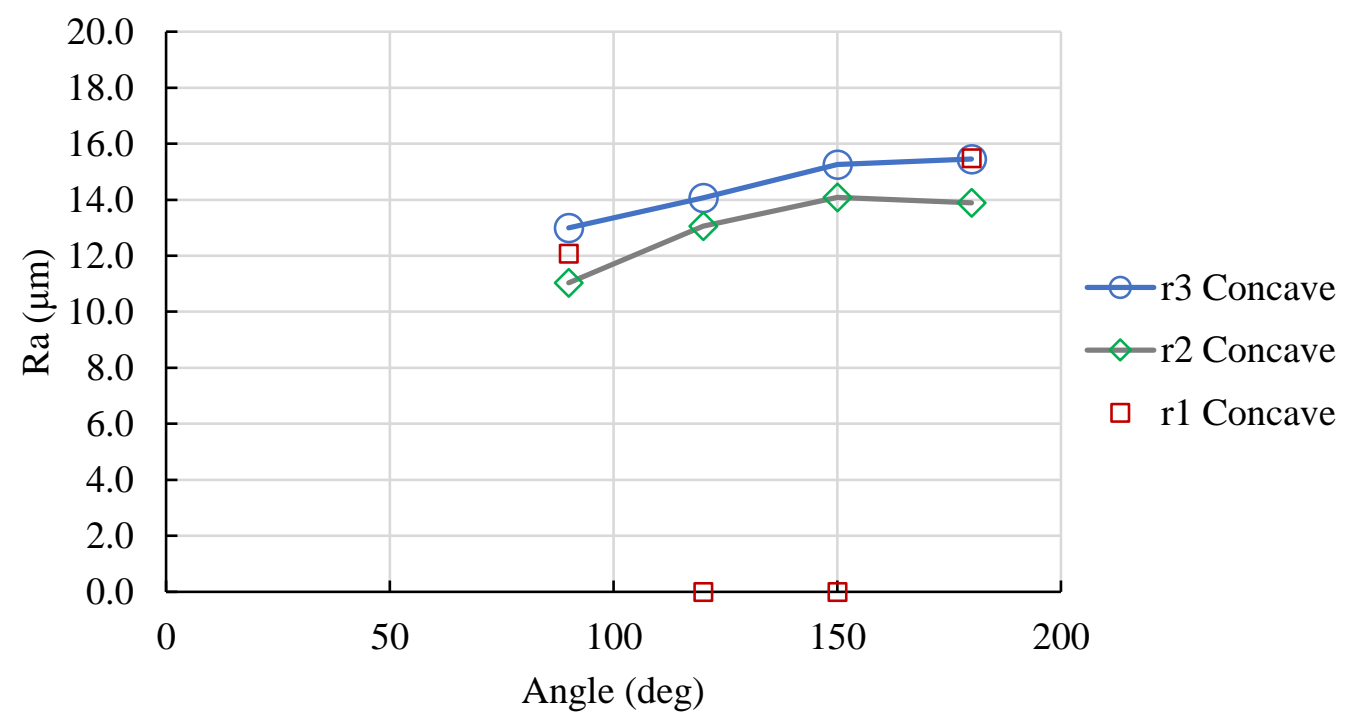




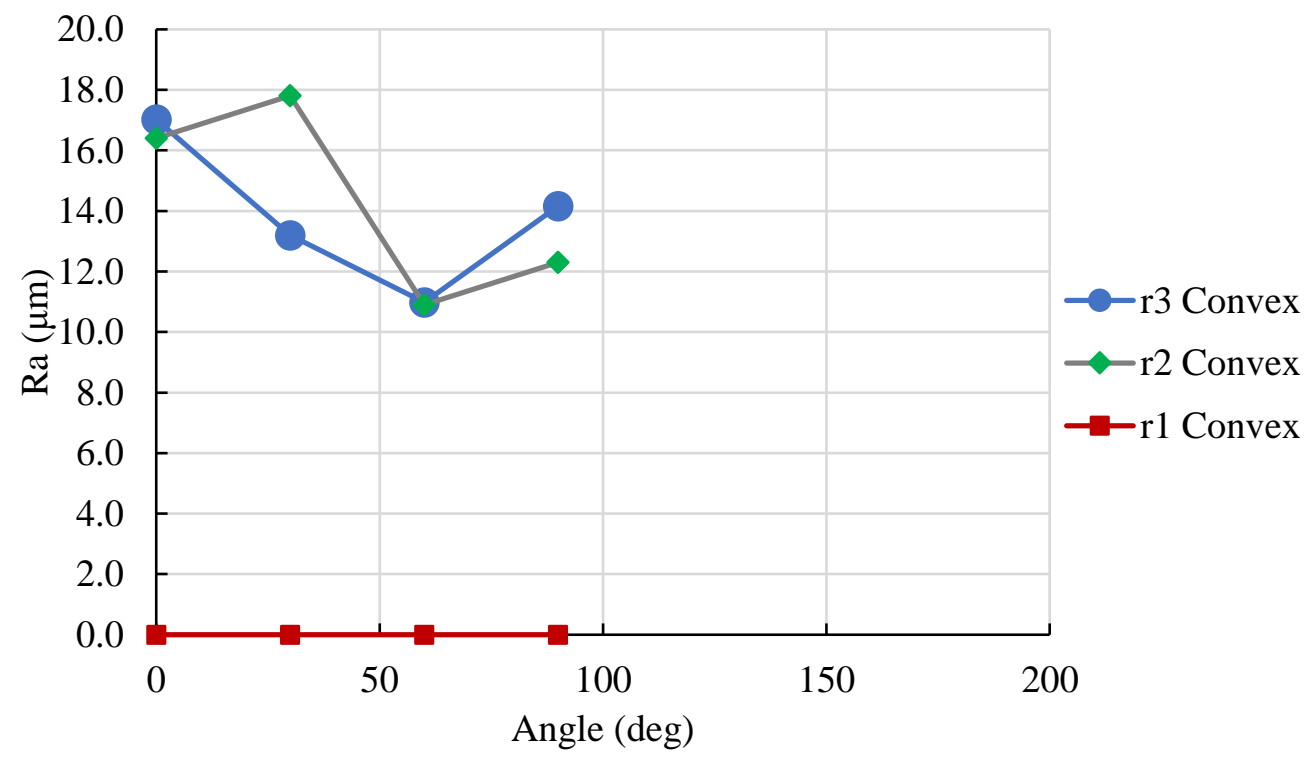

Figure 21. Concave (a) and convex (b) measurements for contour set 4 . 


\section{CONCLUSIONS}

Understanding the relationship that part geometry and parameter values have with the resulting dimensional accuracy and surface quality of SLM fabricated part is crucial to ensure the success of application parts. From literature it is know that the surface roughness and dimensional accuracy of SLM parts can be controlled through adjusting the fabrication parameters, scan strategy and part geometry. Focusing on the effects of contour parameter setting changes for surfaces and hole features on incline planes the individual connections of each variable to surface roughness and dimensionality through the fabrication of a single part design.

For varying contour laser power and scan speed settings there is a clear relationship as the two higher energy densities gave smaller the nominal dimensions while the lower energy density gave higher measured dimensions for the thickness and width measurements. Between surface roughness and dimensional accuracy, the contour parameters have a greater effect on dimensional accuracy. Adjusting not only the laser power and scan speed results in changes to the measured part dimensions, but so does the beam offset parameter.

The part geometry has a greater effect on surface roughness than dimensionality for both the planar surfaces and hole features. The trend for planar surfaces followed a $3^{\text {rd }}$ order polynomial trend whereas the incline angle decreased to $30^{\circ}$ the $R a$ would increase to where it could no longer be measured by the surface profilometer. This was different for the hole features, but both the concave and convex surfaces have the same trend. The side and bottom of each surface were the maximum and minimum $R a$ values for the radiused surface. The two measurements between the endpoints created an almost linear trend between the maximum and minimum measurements. In terms of dimensional accuracy, the closer the overhang surface got to $0^{\circ}$, the more sagging there was. This sagging was not only dependent on part geometry, but also on the contour settings. Based off visual inspection and the point cloud inspection reports for each specimen, shown in 
Appendix A (Figure 22-25), the sagging effect occurs for contour sets 2 and 4, which have the lowest power setting of $60 \mathrm{~W}$ and slower scan speeds. The other two specimens do not have as severe sagging with a power setting of $120 \mathrm{~W}$ and have higher scan speeds.

Overall, a clear relationship between overhanging geometry and contour parameter settings and the dimensional accuracy and surface quality for parts fabricated in 17-4 stainless steel via SLM. Future work should include mechanical property testing of overhang specimens to determine if the incline angle influences mechanical properties. The presence of high surface roughness has been linked to controlling fatigue properties of SLM parts and further investigation of these effects would be beneficial in strengthening the significance of this current research work. 


\section{REFERENCES}

Calignano, F., Peverini, O. A., Addamo, G., \& Iuliano, L. (2020). Accuracy of complex internal channels produced by laser powder bed fusion process. Journal of Manufacturing Processes, 54, 48-53. doi:10.1016/j.jmapro.2020.02.045

Delgado, J., Ciurana, J., \& Rodríguez, C. A. (2012). Influence of process parameters on part quality and mechanical properties for DMLS and SLM with iron-based materials. The International Journal of Advanced Manufacturing Technology, 60(5), 601-610. doi:10.1007/s00170-011-3643-5

Deng, Y., Mao, Z., Yang, N., Niu, X., \& Lu, X. (2020). Collaborative Optimization of Density and Surface Roughness of 316L Stainless Steel in Selective Laser Melting. Materials (Basel, Switzerland), 13(7). doi:10.3390/ma13071601

DePond, P. J., Guss, G., Ly, S., Calta, N. P., Deane, D., Khairallah, S., \& Matthews, M. J. (2018). In situ measurements of layer roughness during laser powder bed fusion additive manufacturing using low coherence scanning interferometry. Materials \& Design, 154, 347-359. doi:10.1016/j.matdes.2018.05.050

Fox, J. C., Moylan, S. P., \& Lane, B. M. (2016). Effect of process parameters on the surface roughness of overhanging structures in laser powder bed fusion additive manufacturing. In M. A. Davies \& R. Msaoubi (Eds.), 3rd Cirp Conference on Surface Integrity (Vol. 45, pp. 131-134). Amsterdam: Elsevier Science Bv.

Gockel, J., Sheridan, L., Koerper, B., \& Whip, B. (2019). The influence of additive manufacturing processing parameters on surface roughness and fatigue life. International Journal of Fatigue, 124, 380-388. doi:10.1016/j.ijfatigue.2019.03.025

Klingaa, C., Dahmen, T., Baier, S., Mohanty, S., \& Hattel, J. (2020). X-ray CT and image analysis methodology for local roughness characterization in cooling channels made by metal additive manufacturing. Additive Manufacturing, 32, 101032. 
Mani, M., Lane, B. M., Donmez, M. A., Feng, S. C., \& Moylan, S. P. (2017). A review on measurement science needs for real-time control of additive manufacturing metal powder bed fusion processes. International Journal of Production Research, 55(5), 1400-1418. doi:10.1080/00207543.2016.1223378

Ni, C., Shi, Y., \& Liu, J. (2019). Effects of inclination angle on surface roughness and corrosion properties of selective laser melted 316L stainless steel. Materials Research Express, 6(3), 9. doi:10.1088/2053-1591/aaf2d3

Shi, W. T., Wang, P., Liu, Y. D., \& Han, G. L. (2019). Experiment of Process Strategy of Selective Laser Melting Forming Metal Nonhorizontal Overhanging Structure. Metals, 9(4), 15. doi:10.3390/met9040385

Solberg, K., Guan, S., Razavi, S. M. J., Welo, T., Chan, K. C., \& Berto, F. (2019). Fatigue of additively manufactured 316L stainless steel: The influence of porosity and surface roughness. Fatigue \& Fracture of Engineering Materials \& Structures, 42(9), 2043-2052. doi:10.1111/ffe.13077

Subbaian Kaliamoorthy, P., Subbiah, R., Bensingh, J., Kader, A., \& Nayak, S. (2020). Benchmarking the complex geometric profiles, dimensional accuracy and surface analysis of printed parts. Rapid Prototyping Journal, 26(2), 319-329. doi:10.1108/rpj-01-2019-0024

Tran, H. C., \& Lo, Y. L. (2019). Systematic approach for determining optimal processing parameters to produce parts with high density in selective laser melting process. International Journal of Advanced Manufacturing Technology, 105(10), 4443-4460. doi:10.1007/s00170-019-04517-0

Wang, D., Yang, Y., Yi, Z., \& Su, X. (2013). Research on the fabricating quality optimization of the overhanging surface in SLM process. The International Journal of Advanced Manufacturing Technology, 65(9), 1471-1484. doi:10.1007/s00170-012-4271-4

Wohlers, T. T., Associates, W., Campbell, I., Caffrey, T., Diegel, O., \& Kowen, J. (2018). Wohlers Report 2018: 3D Printing and Additive Manufacturing State of the Industry : Annual Worldwide Progress Report: Wohlers Associates 


\section{APPENDIX A}

Raw data and measurement output reports for dimensionality for benchmark parts v1 and v2.

Table 5. CMM dimension measurements for contour sets 2 through 5, with power and speed settings noted, along with nominal values for both width and thickness of benchmark v2 overhang bars.

\begin{tabular}{|c|c|c|c|c|c|c|}
\hline & \multicolumn{2}{|c|}{ Power $(\mathrm{W})$} & 60 & 120 & 60 & 120 \\
\hline & \multicolumn{2}{|c|}{ Speed $(\mathrm{mm} / \mathrm{s})$} & 700 & 700 & 350 & 1400 \\
\hline & $\begin{array}{l}\text { Energy } \\
\text { Density } \\
(\mathrm{J} / \mathrm{mm})\end{array}$ & $\mathrm{p} / \mathrm{s}$ & 0.086 & 0.171 & 0.171 & 0.086 \\
\hline \multicolumn{3}{|c|}{ Graph series notation: } & $60 / 700$ & $120 / 700$ & $60 / 350$ & $120 / 1400$ \\
\hline $\begin{array}{c}\text { Overhang } \\
\text { angle }\end{array}$ & Dimension & $\begin{array}{l}\text { Nominal } \\
(\mathrm{mm})\end{array}$ & $\begin{array}{c}\text { Contour Set } \\
2\end{array}$ & $\begin{array}{c}\text { Contour Set } \\
3\end{array}$ & $\begin{array}{c}\text { Contour Set } \\
4\end{array}$ & $\begin{array}{l}\text { Contour } \\
\text { Set } 5\end{array}$ \\
\hline $90^{\circ}$ & width & 18 & 18.259 & 17.756 & 17.385 & 18.245 \\
\hline $70^{\circ}$ & width & 18 & 18.312 & 17.736 & 17.337 & 18.287 \\
\hline $50^{\circ}$ & width & 18 & 18.372 & 17.699 & 17.574 & 18.364 \\
\hline $30^{\circ}$ & width & 18 & 18.312 & 17.523 & 17.443 & 18.333 \\
\hline $90^{\circ}$ & thick & 10 & 10.287 & 9.869 & 9.694 & 10.312 \\
\hline $70^{\circ}$ & thick & 10 & 10.239 & 9.367 & 9.463 & 10.214 \\
\hline $50^{\circ}$ & thick & 10 & 10.384 & 9.813 & 9.812 & 10.413 \\
\hline $30^{\circ}$ & thick & 10 & 9.804 & 9.609 & 9.345 & 10.205 \\
\hline
\end{tabular}


Table 6. Measurement deviations from CAD for v1 benchmark part with varying beam offset settings.

\begin{tabular}{|c|c|c|c|c|c|c|c|c|}
\hline & \multirow{2}{*}{ Contour Set } & \multirow{2}{*}{$\begin{array}{l}\text { Beam Offset } \\
\text { Settings } \\
(\mathrm{mm})\end{array}$} & \multirow{2}{*}{$\begin{array}{c}\text { Run } \\
\#\end{array}$} & \multicolumn{5}{|c|}{ Overhang Angle } \\
\hline & & & & $90^{\circ}$ & $75^{\circ}$ & $60^{\circ}$ & $45^{\circ}$ & $30^{\circ}$ \\
\hline \multirow{10}{*}{ 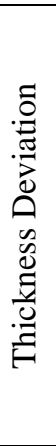 } & \multirow{5}{*}{1} & \multirow{5}{*}{$.08 / 0$} & 1 & 0.06 & 0.06 & 0.18 & 0.31 & 0.45 \\
\hline & & & 2 & 0.04 & 0.07 & 0.21 & 0.34 & 0.44 \\
\hline & & & 3 & 0.02 & 0.09 & 0.17 & 0.31 & 0.48 \\
\hline & & & 4 & 0.05 & 0.05 & 0.21 & 0.33 & 0.46 \\
\hline & & & 5 & 0.03 & 0.07 & 0.22 & 0.31 & 0.45 \\
\hline & \multirow{5}{*}{2} & \multirow{5}{*}{$.1 / .08$} & 1 & 0.05 & 0.09 & 0.12 & 0.21 & 0.32 \\
\hline & & & 2 & 0.06 & 0.08 & 0.14 & 0.23 & 0.37 \\
\hline & & & 3 & 0.07 & 0.09 & 0.15 & 0.19 & 0.36 \\
\hline & & & 4 & 0.09 & 0.1 & 0.13 & 0.2 & 0.33 \\
\hline & & & 5 & 0.06 & 0.09 & 0.15 & 0.2 & 0.35 \\
\hline \multirow{10}{*}{ 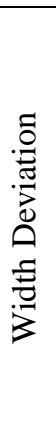 } & \multirow{5}{*}{1} & \multirow{5}{*}{$.08 / 0$} & 1 & 0.06 & 0.05 & 0.07 & 0.04 & 0.06 \\
\hline & & & 2 & 0.06 & 0.03 & 0.06 & 0.06 & 0.05 \\
\hline & & & 3 & 0.07 & 0.04 & 0.06 & 0.07 & 0.05 \\
\hline & & & 4 & 0.05 & 0.03 & 0.06 & 0.04 & 0.06 \\
\hline & & & 5 & 0.06 & 0.06 & 0.03 & 0.04 & 0.04 \\
\hline & \multirow{5}{*}{2} & \multirow{5}{*}{$.1 / .08$} & 1 & 0.12 & 0.09 & 0.09 & 0.09 & 0.07 \\
\hline & & & 2 & 0.11 & 0.08 & 0.09 & 0.07 & 0.09 \\
\hline & & & 3 & 0.08 & 0.09 & 0.09 & 0.11 & 0.07 \\
\hline & & & 4 & 0.1 & 0.07 & 0.07 & 0.07 & 0.06 \\
\hline & & & 5 & 0.09 & 0.11 & 0.08 & 0.09 & 0.09 \\
\hline
\end{tabular}

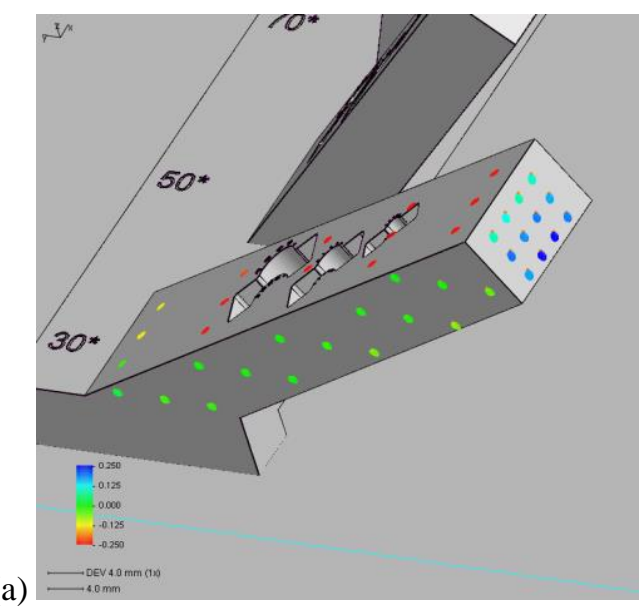

(b)

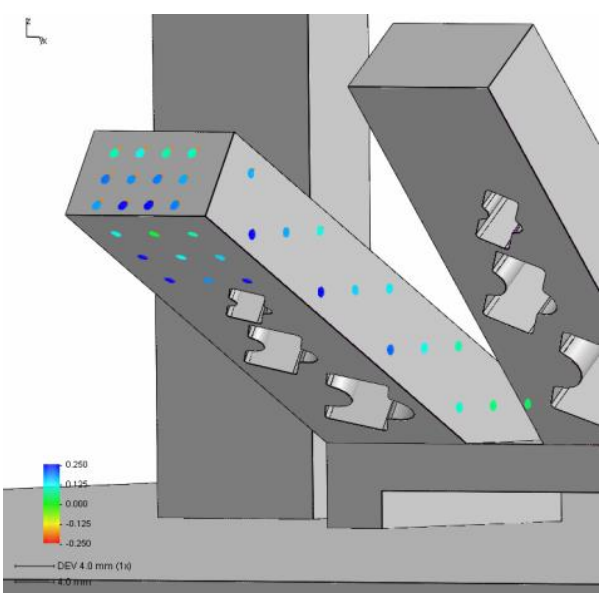



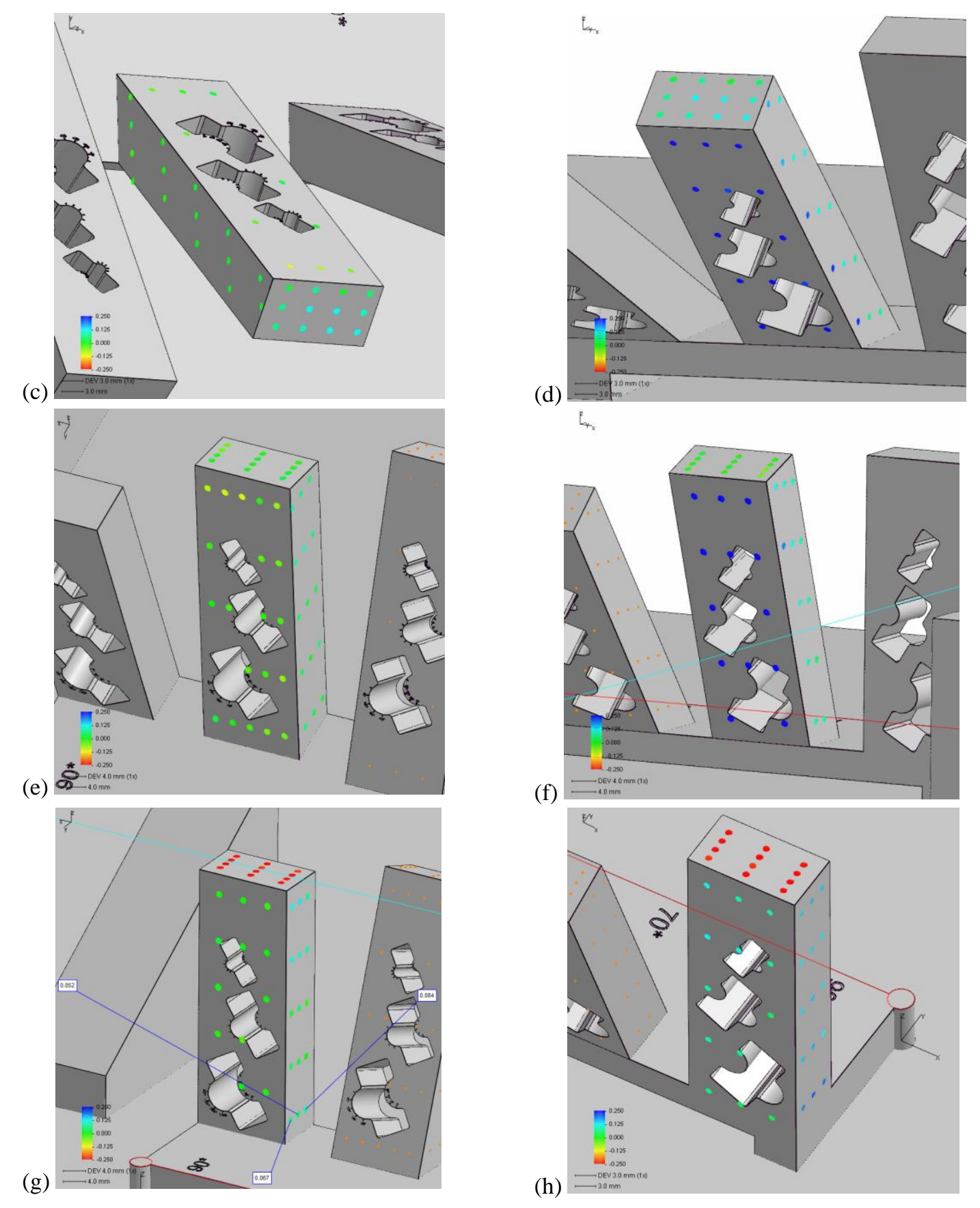

Figure 22. Point cloud visual display for contour set 2 with point cloud deviations at (a-b) $30^{\circ}$ (c-d) $50^{\circ}$, (e-f) $70^{\circ}$, and (g-h) $90^{\circ}$ overhang planes. 

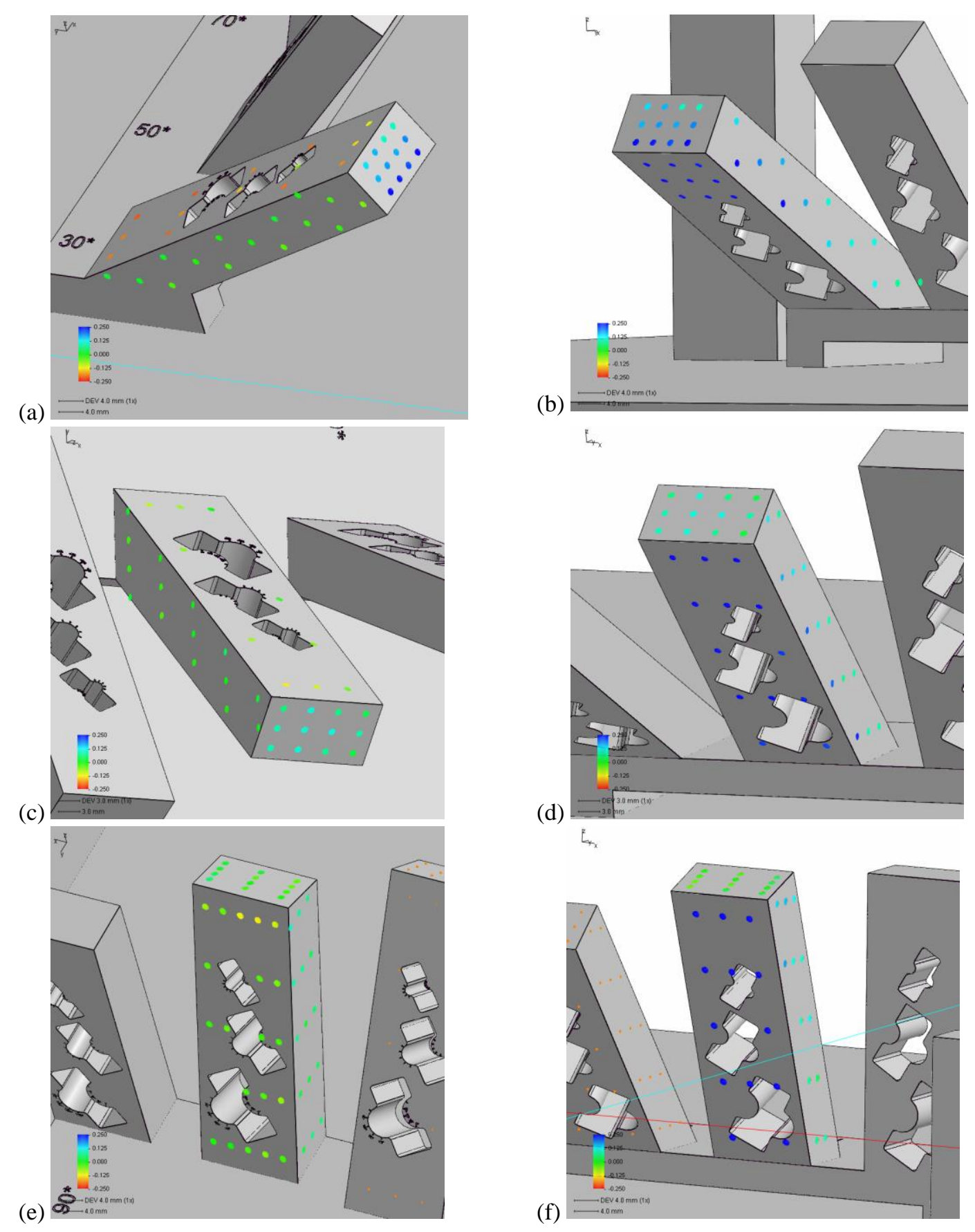

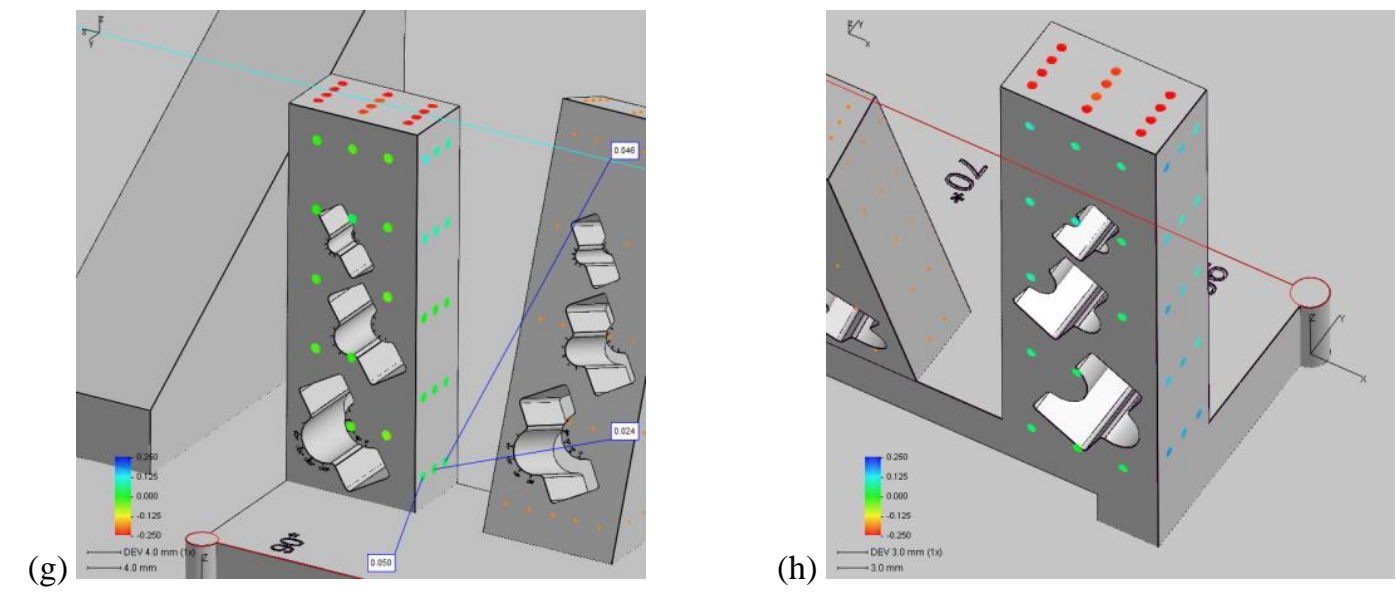

Figure 23. Point cloud visual display for contour set 3 with point cloud deviations at (a-b) $30^{\circ}$ (c-d) $50^{\circ}$, (e-f) $70^{\circ}$, and (g-h) $90^{\circ}$ overhang planes.

(a)

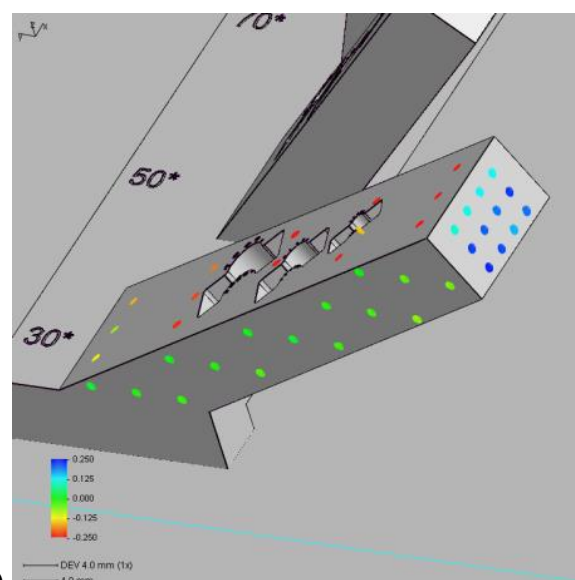

(c)

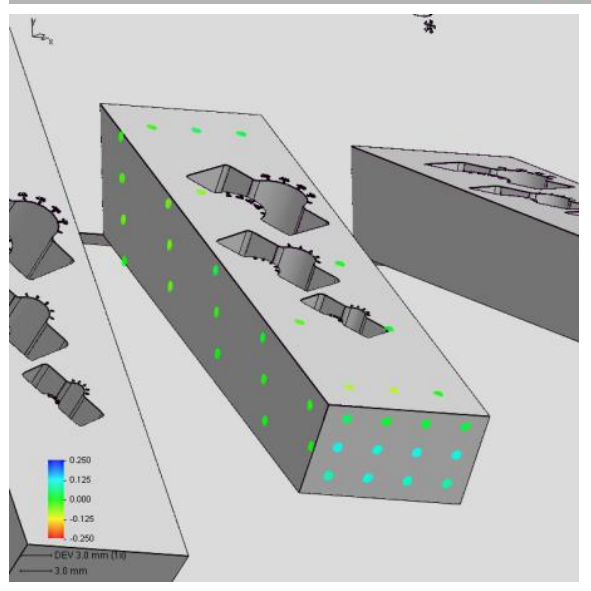

(b)

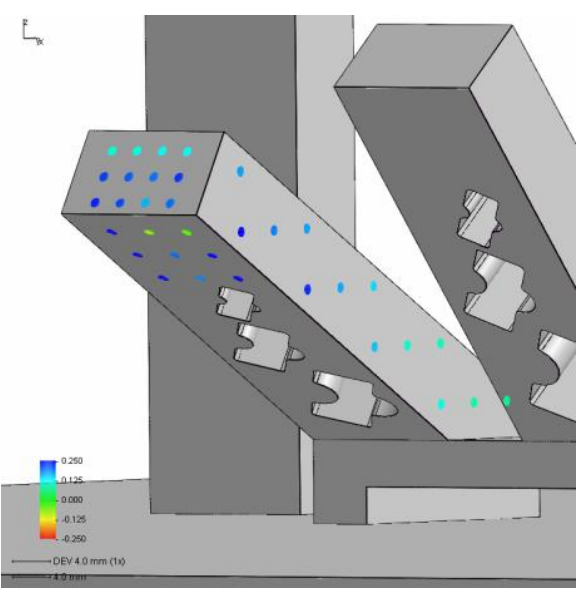

$L_{x}$

(d)

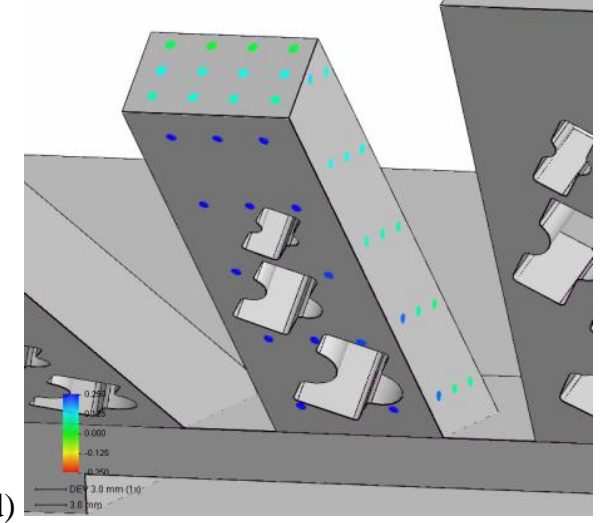



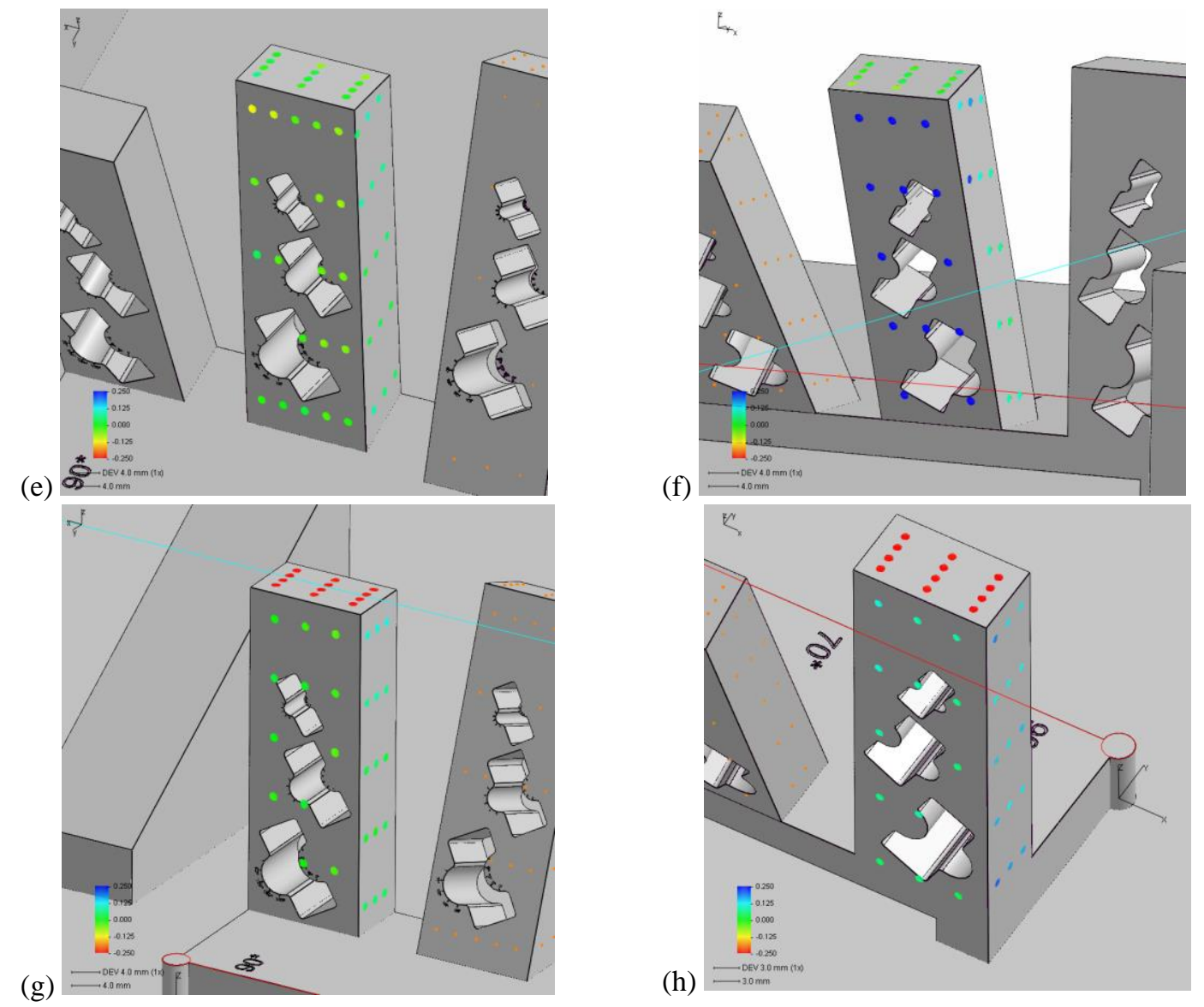

Figure 24. Point cloud visual display for contour set 4 with point cloud deviations at (a-b) $30^{\circ}$ (c-d) $50^{\circ}$, (e-f) $70^{\circ}$, and (g-h) $90^{\circ}$ overhang planes.
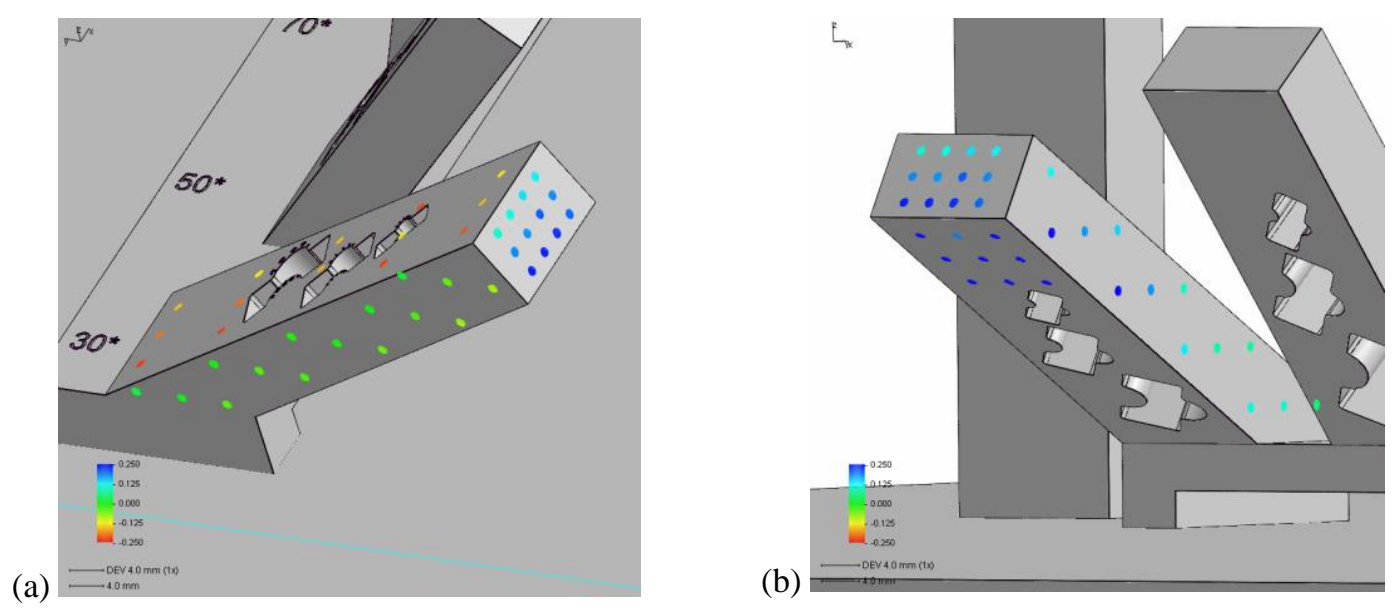

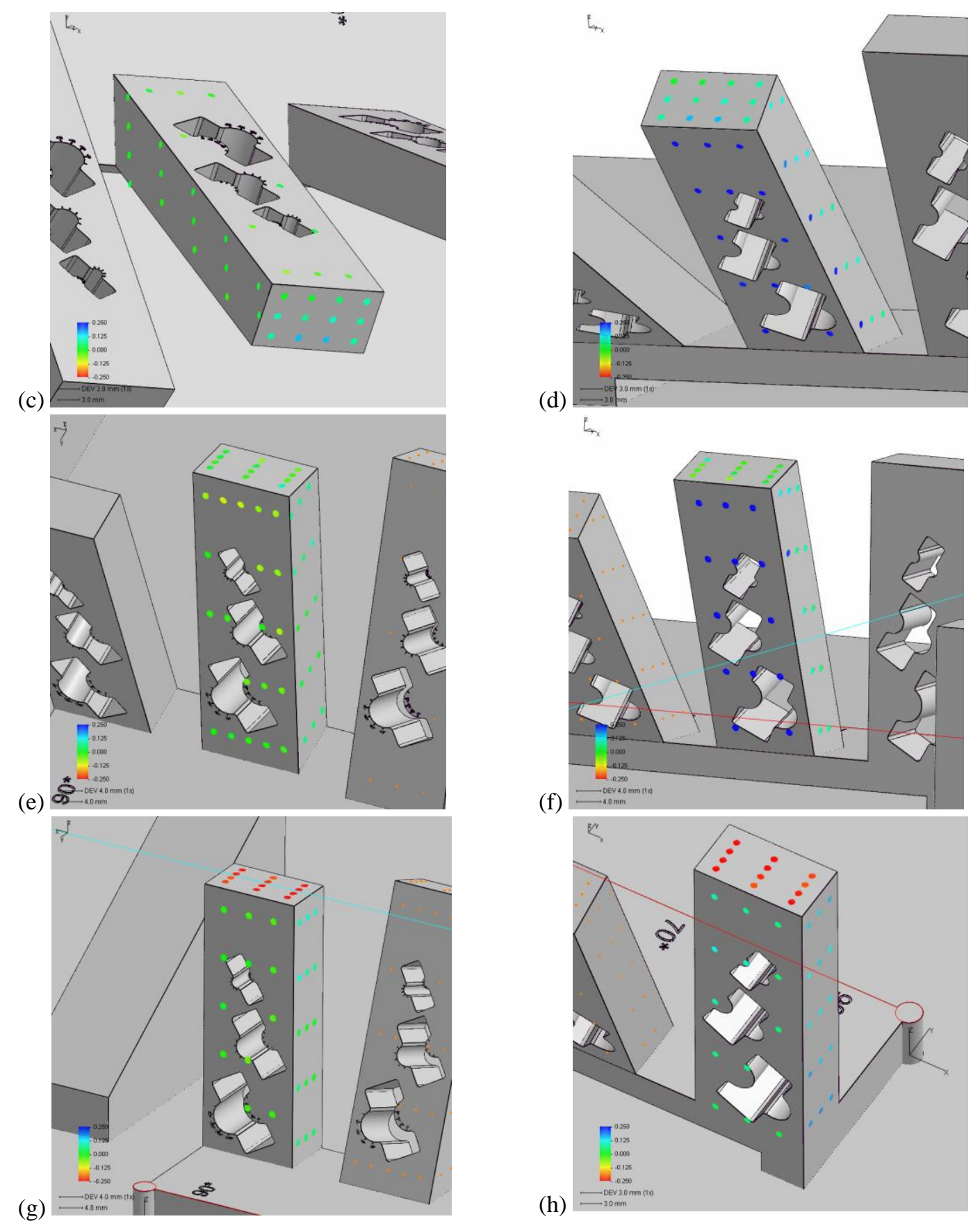

Figure 25. Point cloud visual display for contour set 5 with point cloud deviations at (a-b) $30^{\circ}$ (c-d) $50^{\circ}$, (e-f) $70^{\circ}$, and (g-h) $90^{\circ}$ overhang planes. 
Table 7. Downface flatness callout from CMM program for contour sets 2 through 5 for all overhang bars on specimen.

\begin{tabular}{|c|c|c|c|c|}
\hline Laser Power/ Scan Speed & $60 / 700$ & $120 / 700$ & $60 / 350$ & $120 / 1400$ \\
\hline Overhang Angle & Block 1 & Block 2 & Block 3 & Block 4 \\
\hline 90 & 0.011 & 0.033 & 0.016 & 0.04 \\
\hline 70 & 0.023 & 0.046 & 0.018 & 0.043 \\
\hline 50 & 0.072 & 0.068 & 0.025 & 0.081 \\
\hline 30 & 0.372 & 0.205 & 0.431 & 0.118 \\
\hline
\end{tabular}




\section{APPENDIX B}

Organized raw data of surface roughness for benchmark part v2. A “_“ symbolizes there is no data for that point due to the profilometer's inability to get a reading within its range, or there was no clear access point for the measurement location. The standard deviation and average for the three measurement runs are included in the tables.

Table 8. Surface profilometer measurements of $R a$ for each feature on benchmark specimen v2 built with contour set 2 .

\begin{tabular}{|c|c|c|c|c|c|c|c|}
\hline \multicolumn{3}{|c|}{ Feature } & \multicolumn{5}{|c|}{$\mathbf{R a}(\mu \mathrm{m})$} \\
\hline $\begin{array}{c}\text { Overhang } \\
\text { Angle }\end{array}$ & Hole/Plane & Angle & Run 1 & Run 3 & Run 3 & STD DEV & AVG \\
\hline \multirow{3}{*}{30} & Upface & \multirow{3}{*}{-} & 17.020 & 18.225 & 18.022 & 0.645 & 17.756 \\
\hline & Downface & & & & & - & - \\
\hline & Topface & & 11.335 & 12.669 & 11.579 & 0.710 & 11.861 \\
\hline \multirow{3}{*}{50} & Upface & \multirow{3}{*}{-} & 16.044 & 15.601 & 15.225 & 0.410 & 15.623 \\
\hline & Downface & & 25.069 & 31.656 & 26.393 & 3.484 & 27.706 \\
\hline & Topface & & 11.017 & 12.013 & 13.573 & 1.288 & 12.201 \\
\hline \multirow{3}{*}{70} & Upface & \multirow{3}{*}{-} & 17.625 & 15.819 & 17.985 & 1.161 & 17.143 \\
\hline & Downface & & 14.494 & 14.041 & 13.222 & 0.645 & 13.919 \\
\hline & Topface & & 11.790 & 12.289 & 12.599 & 0.408 & 12.226 \\
\hline \multirow{3}{*}{90} & Upface & \multirow{3}{*}{ - } & 12.355 & 11.822 & 6.124 & 3.454 & 10.100 \\
\hline & Downface & & 13.245 & 12.869 & 13.699 & 0.416 & 13.271 \\
\hline & Topface & & 4.095 & 3.669 & 4.942 & 0.648 & 4.235 \\
\hline \multirow{16}{*}{30} & \multirow{4}{*}{ r3- concave } & 180 & 17.527 & 17.119 & 18.890 & 0.927 & 17.845 \\
\hline & & 150 & 16.564 & 15.791 & 14.273 & 1.166 & 15.543 \\
\hline & & 120 & 13.442 & 14.460 & 12.881 & 0.800 & 13.594 \\
\hline & & 90 & 11.943 & 12.806 & 11.419 & 0.700 & 12.056 \\
\hline & \multirow{4}{*}{ r3 - convex } & 0 & 15.486 & 17.292 & 15.112 & 1.166 & 15.963 \\
\hline & & 30 & 16.868 & 14.764 & 16.475 & 1.119 & 16.036 \\
\hline & & 60 & 11.169 & 11.763 & 11.191 & 0.337 & 11.374 \\
\hline & & 90 & 15.155 & 13.919 & 15.142 & 0.710 & 14.739 \\
\hline & \multirow{4}{*}{ r2- concave } & 180 & 13.643 & 15.723 & 13.306 & 1.309 & 14.224 \\
\hline & & 150 & 13.727 & 13.704 & 13.180 & 0.309 & 13.537 \\
\hline & & 120 & 13.567 & 12.195 & 13.607 & 0.804 & 13.123 \\
\hline & & 90 & 11.243 & 12.229 & 12.809 & 0.792 & 12.094 \\
\hline & \multirow{4}{*}{ r2 - convex } & 0 & 17.012 & 13.260 & 18.109 & 2.543 & 16.127 \\
\hline & & 30 & 15.210 & 14.212 & 17.274 & 1.562 & 15.565 \\
\hline & & 60 & 12.641 & 12.592 & 12.910 & 0.171 & 12.714 \\
\hline & & 90 & 14.714 & 14.459 & 14.751 & 0.159 & 14.641 \\
\hline
\end{tabular}




\begin{tabular}{|c|c|c|c|c|c|c|c|}
\hline & \multirow{4}{*}{ r1- concave } & 180 & 16.751 & 16.366 & 13.976 & 1.503 & 15.698 \\
\hline & & 150 & & & & - & - \\
\hline & & 120 & & & & - & - \\
\hline & & 90 & 11.416 & 13.811 & 15.000 & 1.826 & 13.409 \\
\hline & \multirow{4}{*}{ r1 - convex } & 0 & & & & - & - \\
\hline & & 30 & & & & - & - \\
\hline & & 60 & & & & - & - \\
\hline & & 90 & & & & - & - \\
\hline \multirow{24}{*}{50} & \multirow{4}{*}{ r3- concave } & 180 & 13.666 & 15.290 & 14.798 & 0.833 & 14.585 \\
\hline & & 150 & 19.050 & 17.622 & 17.036 & 1.036 & 17.903 \\
\hline & & 120 & 12.290 & 13.954 & 12.548 & 0.896 & 12.931 \\
\hline & & 90 & 13.762 & 13.224 & 14.421 & 0.600 & 13.802 \\
\hline & \multirow{4}{*}{ r3 - convex } & 0 & & & & - & - \\
\hline & & 30 & 24.231 & 20.726 & 21.394 & 1.861 & 22.117 \\
\hline & & 60 & 15.800 & 15.136 & 16.330 & 0.598 & 15.755 \\
\hline & & 90 & 11.711 & 13.064 & 13.146 & 0.806 & 12.640 \\
\hline & \multirow{4}{*}{ r2- concave } & 180 & 18.424 & 17.806 & 19.111 & 0.653 & 18.447 \\
\hline & & 150 & 15.023 & 13.545 & 15.246 & 0.924 & 14.605 \\
\hline & & 120 & 12.099 & 13.178 & 13.005 & 0.580 & 12.761 \\
\hline & & 90 & 11.004 & 11.503 & 10.710 & 0.401 & 11.072 \\
\hline & \multirow{4}{*}{ r2 - convex } & 0 & & & & - & - \\
\hline & & 30 & 23.173 & 22.519 & 22.111 & 0.536 & 22.601 \\
\hline & & 60 & 15.168 & 14.843 & 15.896 & 0.539 & 15.302 \\
\hline & & 90 & 13.509 & 13.067 & 11.651 & 0.971 & 12.742 \\
\hline & \multirow{4}{*}{ r1- concave } & 180 & 14.657 & 15.121 & 15.019 & 0.244 & 14.932 \\
\hline & & 150 & & & & - & - \\
\hline & & 120 & & & & - & - \\
\hline & & 90 & 17.963 & 17.757 & 18.218 & 0.231 & 17.979 \\
\hline & \multirow{4}{*}{ r1 - convex } & 0 & & & & - & - \\
\hline & & 30 & 26.042 & & & - & 26.042 \\
\hline & & 60 & & & & - & - \\
\hline & & 90 & & & & - & - \\
\hline \multirow{11}{*}{70} & \multirow{4}{*}{ r3- concave } & 180 & 17.838 & 19.364 & 17.298 & 1.071 & 18.167 \\
\hline & & 150 & 24.636 & 15.930 & 22.335 & 4.511 & 20.967 \\
\hline & & 120 & 16.472 & 16.639 & 15.425 & 0.658 & 16.179 \\
\hline & & 90 & & & & - & - \\
\hline & \multirow{4}{*}{ r3 - convex } & 0 & & & & - & - \\
\hline & & 30 & & & & - & - \\
\hline & & 60 & 11.316 & 11.316 & 13.553 & 1.292 & 12.062 \\
\hline & & 90 & 13.703 & 15.031 & 13.898 & 0.717 & 14.211 \\
\hline & \multirow{3}{*}{ r2- concave } & 180 & 15.161 & 15.579 & 15.511 & 0.224 & 15.417 \\
\hline & & 150 & 18.146 & 15.489 & 15.194 & 1.626 & 16.276 \\
\hline & & 120 & 14.325 & 13.965 & 13.566 & 0.380 & 13.952 \\
\hline
\end{tabular}




\begin{tabular}{|c|c|c|c|c|c|c|c|}
\hline & & 90 & 13.395 & 12.952 & 12.734 & 0.337 & 13.027 \\
\hline & \multirow{4}{*}{ r2 - convex } & 0 & & & & - & - \\
\hline & & 30 & & & & - & - \\
\hline & & 60 & 12.516 & 13.729 & 12.045 & 0.869 & 12.763 \\
\hline & & 90 & 11.432 & 11.316 & 14.024 & 1.531 & 12.257 \\
\hline & \multirow{4}{*}{ r1- concave } & 180 & 19.604 & 19.313 & 19.081 & 0.262 & 19.333 \\
\hline & & 150 & & & & - & - \\
\hline & & 120 & & & & - & - \\
\hline & & 90 & 13.067 & 13.835 & 16.024 & 1.534 & 14.309 \\
\hline & \multirow{4}{*}{ r1 - convex } & 0 & & & & - & - \\
\hline & & 30 & & & & - & - \\
\hline & & 60 & & & & - & - \\
\hline & & 90 & & & & - & - \\
\hline \multirow{24}{*}{90} & \multirow{4}{*}{ r3- concave } & 180 & 5.429 & 3.769 & 5.594 & 1.009 & 4.931 \\
\hline & & 150 & & & & - & - \\
\hline & & 120 & & & & - & - \\
\hline & & 90 & & & & - & - \\
\hline & \multirow{4}{*}{ r3 - convex } & 0 & & & & - & - \\
\hline & & 30 & & & & - & - \\
\hline & & 60 & & & & - & - \\
\hline & & 90 & & & & - & - \\
\hline & \multirow{4}{*}{ r2- concave } & 180 & 7.725 & 18.405 & 17.691 & 5.971 & 14.607 \\
\hline & & 150 & 14.192 & 16.554 & 15.626 & 1.190 & 15.457 \\
\hline & & 120 & 16.504 & 17.186 & 19.393 & 1.510 & 17.694 \\
\hline & & 90 & 9.302 & 9.442 & 9.821 & 0.269 & 9.522 \\
\hline & \multirow{4}{*}{ r2 - convex } & 0 & & & & - & - \\
\hline & & 30 & & & & - & - \\
\hline & & 60 & 13.760 & 19.351 & 16.605 & 2.796 & 16.572 \\
\hline & & 90 & 11.937 & 12.892 & 10.823 & 1.036 & 11.884 \\
\hline & \multirow{4}{*}{ r1- concave } & 180 & 10.352 & 10.123 & 9.643 & 0.362 & 10.039 \\
\hline & & 150 & & & & - & - \\
\hline & & 120 & & & & - & - \\
\hline & & 90 & 17.253 & 12.876 & 17.876 & 2.725 & 16.002 \\
\hline & \multirow{4}{*}{ r1 - convex } & 0 & & & & - & - \\
\hline & & 30 & & & & - & - \\
\hline & & 60 & & & & - & - \\
\hline & & 90 & & & & - & - \\
\hline
\end{tabular}

Table 9. Surface profilometer measurements of $R a$ for each feature on benchmark specimen v2 built with contour set 3 .

\section{Feature}

\section{$\operatorname{Ra}(\mu \mathbf{m})$}




\begin{tabular}{|c|c|c|c|c|c|c|c|}
\hline $\begin{array}{c}\text { Overhang } \\
\text { Angle }\end{array}$ & Hole/Plane & $\begin{array}{c}\text { Side \& } \\
\text { Angle }\end{array}$ & Run 1 & Run 2 & Run 3 & STD DEV & AVG \\
\hline \multirow{3}{*}{30} & Upface & \multirow{3}{*}{-} & 12.955 & 15.806 & 18.146 & 2.600 & 15.636 \\
\hline & Downface & & & & & - & - \\
\hline & Topface & & 11.370 & 15.612 & 13.843 & 2.131 & 13.608 \\
\hline \multirow{3}{*}{50} & Upface & \multirow{3}{*}{-} & 15.820 & 16.405 & 16.262 & 0.305 & 16.162 \\
\hline & Downface & & 30.571 & 24.039 & 27.385 & 3.266 & 27.332 \\
\hline & Topface & & 11.643 & 15.539 & 20.636 & 4.510 & 15.939 \\
\hline \multirow{3}{*}{70} & Upface & \multirow{3}{*}{-} & 14.416 & 16.100 & 14.703 & 0.901 & 15.073 \\
\hline & Downface & & 14.900 & 14.586 & 14.678 & 0.161 & 14.721 \\
\hline & Topface & & 13.457 & 14.881 & 12.365 & 1.262 & 13.568 \\
\hline \multirow{3}{*}{90} & Upface & \multirow{3}{*}{-} & 12.594 & 14.319 & 11.660 & 1.349 & 12.858 \\
\hline & Downface & & 15.343 & 12.475 & 12.451 & 1.663 & 13.423 \\
\hline & Topface & & 4.056 & 4.585 & 2.776 & 0.930 & 3.806 \\
\hline \multirow{24}{*}{30} & \multirow{4}{*}{ r3- concave } & 180 & 16.039 & 15.723 & 14.538 & 0.791 & 15.433 \\
\hline & & 150 & 13.174 & 13.000 & 14.611 & 0.884 & 13.595 \\
\hline & & 120 & 11.514 & 11.601 & 12.305 & 0.434 & 11.807 \\
\hline & & 90 & 13.619 & 13.943 & 13.872 & 0.170 & 13.811 \\
\hline & \multirow{4}{*}{ r3 - convex } & 0 & 16.319 & 18.261 & 15.544 & 1.400 & 16.708 \\
\hline & & 30 & 15.734 & 15.940 & 15.179 & 0.394 & 15.618 \\
\hline & & 60 & 12.240 & 13.297 & 13.554 & 0.696 & 13.030 \\
\hline & & 90 & 15.481 & 15.043 & 13.919 & 0.806 & 14.814 \\
\hline & \multirow{4}{*}{ r2- concave } & 180 & 13.439 & 15.404 & 15.093 & 1.056 & 14.645 \\
\hline & & 150 & 11.425 & 10.859 & 11.840 & 0.492 & 11.375 \\
\hline & & 120 & 14.515 & 13.763 & 7.250 & 3.995 & 11.843 \\
\hline & & 90 & 12.246 & 12.058 & 11.972 & 0.140 & 12.092 \\
\hline & \multirow{4}{*}{$\mathrm{r} 2$ - convex } & 0 & 14.629 & 15.372 & 15.277 & 0.404 & 15.093 \\
\hline & & 30 & 14.842 & 14.808 & 14.990 & 0.097 & 14.880 \\
\hline & & 60 & 14.008 & 13.092 & 13.573 & 0.458 & 13.558 \\
\hline & & 90 & 15.629 & 16.331 & 16.335 & 0.406 & 16.098 \\
\hline & \multirow{4}{*}{ r1- concave } & 180 & 17.412 & 16.463 & 16.555 & 0.523 & 16.810 \\
\hline & & 150 & 13.609 & 13.612 & 14.227 & 0.356 & 13.816 \\
\hline & & 120 & & & & - & - \\
\hline & & 90 & 14.569 & 13.570 & 13.752 & 0.532 & 13.964 \\
\hline & \multirow{4}{*}{ r1 - convex } & 0 & 16.751 & 16.502 & 17.542 & 0.543 & 16.932 \\
\hline & & 30 & 14.498 & 16.164 & 12.667 & 1.749 & 14.443 \\
\hline & & 60 & 13.316 & 12.868 & 12.595 & 0.364 & 12.926 \\
\hline & & 90 & & & & - & - \\
\hline \multirow{5}{*}{50} & \multirow{4}{*}{ r3- concave } & 180 & 15.592 & 16.595 & 17.269 & 0.844 & 16.485 \\
\hline & & 150 & 17.200 & 16.384 & 17.418 & 0.545 & 17.001 \\
\hline & & 120 & 14.854 & 16.546 & 15.156 & 0.902 & 15.519 \\
\hline & & 90 & 12.623 & 12.084 & 11.230 & 0.702 & 11.979 \\
\hline & r3 - convex & 0 & 24.337 & 22.599 & 21.366 & 1.493 & 22.767 \\
\hline
\end{tabular}




\begin{tabular}{|c|c|c|c|c|c|c|c|}
\hline & & 30 & 25.668 & 21.204 & 23.486 & 2.232 & 23.453 \\
\hline & & 60 & 11.665 & 11.613 & 13.990 & 1.358 & 12.423 \\
\hline & & 90 & 11.990 & 13.192 & 14.061 & 1.040 & 13.081 \\
\hline & & 180 & 16.834 & 16.647 & 16.578 & 0.132 & 16.686 \\
\hline & r2-concave & 150 & 18.940 & 18.940 & 17.592 & 0.778 & 18.491 \\
\hline & Iz-concave & 120 & 15.038 & 14.130 & 15.307 & 0.617 & 14.825 \\
\hline & & 90 & 11.059 & 12.185 & 12.226 & 0.662 & 11.823 \\
\hline & & 0 & 21.267 & 19.043 & 19.954 & 1.118 & 20.088 \\
\hline & $r^{2}-$ convex & 30 & 19.324 & 16.700 & 19.447 & 1.552 & 18.490 \\
\hline & $12-\operatorname{con} 11 \mathrm{x}$ & 60 & 12.513 & 11.886 & 13.365 & 0.742 & 12.588 \\
\hline & & 90 & 12.250 & 14.301 & 12.689 & 1.080 & 13.080 \\
\hline & & 180 & 15.859 & 15.485 & 15.933 & 0.240 & 15.759 \\
\hline & $\mathrm{r} 1$-concave & 150 & 16.346 & 15.405 & 16.406 & 0.561 & 16.052 \\
\hline & 11-concave & 120 & & & & - & - \\
\hline & & 90 & 19.123 & 16.975 & 18.325 & 1.086 & 18.141 \\
\hline & & 0 & 25.983 & 22.951 & 23.031 & 1.728 & 23.988 \\
\hline & & 30 & 17.470 & 17.208 & 16.050 & 0.756 & 16.909 \\
\hline & r1 - convex & 60 & & & & - & - \\
\hline & & 90 & & & & - & - \\
\hline \multirow{24}{*}{70} & \multirow{4}{*}{ r3- concave } & 180 & 15.010 & 14.529 & 16.339 & 0.938 & 15.293 \\
\hline & & 150 & 15.988 & 13.704 & 17.190 & 1.771 & 15.627 \\
\hline & & 120 & & & & - & - \\
\hline & & 90 & & & & - & - \\
\hline & \multirow{4}{*}{ r3 - convex } & 0 & & & & - & - \\
\hline & & 30 & & & & - & - \\
\hline & & 60 & & & & - & - \\
\hline & & 90 & 10.244 & 11.219 & 11.046 & 0.520 & 10.836 \\
\hline & \multirow{4}{*}{ r2- concave } & 180 & 18.792 & 17.302 & 17.121 & 0.917 & 17.738 \\
\hline & & 150 & 15.564 & 15.014 & 15.446 & 0.290 & 15.341 \\
\hline & & 120 & 15.093 & 14.676 & 14.731 & 0.227 & 14.833 \\
\hline & & 90 & 13.632 & 13.098 & 14.650 & 0.788 & 13.793 \\
\hline & \multirow{4}{*}{ r2 - convex } & 0 & & & & - & - \\
\hline & & 30 & 20.438 & 23.940 & 23.724 & 1.963 & 22.701 \\
\hline & & 60 & 12.973 & 15.649 & 14.236 & 1.339 & 14.286 \\
\hline & & 90 & 13.812 & 14.211 & 12.559 & 0.862 & 13.527 \\
\hline & \multirow{4}{*}{ r1- concave } & 180 & 17.302 & 17.084 & 16.993 & 0.159 & 17.126 \\
\hline & & 150 & & & & - & - \\
\hline & & 120 & & & & - & - \\
\hline & & 90 & 15.704 & 17.828 & 17.629 & 1.173 & 17.054 \\
\hline & \multirow{4}{*}{ r1 - convex } & 0 & & & & - & - \\
\hline & & 30 & & & & - & - \\
\hline & & 60 & & & & - & - \\
\hline & & 90 & & & & - & - \\
\hline
\end{tabular}




\begin{tabular}{|c|c|c|c|c|c|c|c|}
\hline \multirow{24}{*}{90} & \multirow{4}{*}{ r3- concave } & 180 & & & & - & - \\
\hline & & 150 & & & & - & - \\
\hline & & 120 & & & & - & - \\
\hline & & 90 & & & & - & - \\
\hline & \multirow{4}{*}{ r3 - convex } & 0 & & & & - & - \\
\hline & & 30 & & & & - & - \\
\hline & & 60 & & & & - & - \\
\hline & & 90 & & & & - & - \\
\hline & \multirow{4}{*}{ r2- concave } & 180 & 19.519 & 6.42 & 6.179 & 7.633233 & 10.706 \\
\hline & & 150 & 14.059 & 12.118 & 11.392 & 1.378855 & 12.523 \\
\hline & & 120 & 13.087 & 14.298 & 13.483 & 0.617463 & 13.62267 \\
\hline & & 90 & 13.029 & 11.638 & 11.017 & 1.030264 & 11.89467 \\
\hline & \multirow{4}{*}{ r2 - convex } & 0 & & & & - & - \\
\hline & & 30 & & & & - & - \\
\hline & & 60 & 27.395 & 13.481 & 15.147 & 7.598119 & 18.67433 \\
\hline & & 90 & 14.022 & 13.771 & 13.011 & 0.526422 & 13.60133 \\
\hline & \multirow{4}{*}{ r1- concave } & 180 & & & & - & - \\
\hline & & 150 & & & & - & - \\
\hline & & 120 & & & & - & - \\
\hline & & 90 & 14.113 & 12.82 & 16.223 & 1.717768 & 14.38533 \\
\hline & \multirow{4}{*}{ r1 - convex } & 0 & & & & - & - \\
\hline & & 30 & & & & - & - \\
\hline & & 60 & & & & - & - \\
\hline & & 90 & & & & - & - \\
\hline
\end{tabular}

Table 10. Surface profilometer measurements of $R a$ for each feature on benchmark specimen v2 built with contour set 4 .

\begin{tabular}{|c|c|c|c|c|c|c|c|}
\hline \multicolumn{3}{|c|}{ Feature } & \multicolumn{5}{|c|}{$\operatorname{Ra}(\mu \mathrm{m})$} \\
\hline $\begin{array}{c}\text { Overhang } \\
\text { Angle }\end{array}$ & Hole/Plane & $\begin{array}{c}\text { Side \& } \\
\text { Angle }\end{array}$ & Run 1 & Run 2 & Run 3 & STD DEV & AVG \\
\hline \multirow{3}{*}{30} & Upface & \multirow{3}{*}{ - } & 16.389 & 15.776 & 18.040 & 1.171 & 16.735 \\
\hline & Downface & & & & & - & - \\
\hline & Topface & & 14.763 & 13.324 & 13.321 & 0.832 & 13.803 \\
\hline \multirow{3}{*}{50} & Upface & \multirow{3}{*}{-} & 8.183 & 18.454 & 15.228 & 5.253 & 13.955 \\
\hline & Downface & & 32.558 & 23.667 & 27.225 & 4.475 & 27.817 \\
\hline & Topface & & 15.443 & 11.598 & 14.410 & 1.990 & 13.817 \\
\hline \multirow{3}{*}{70} & Upface & \multirow{3}{*}{-} & 14.964 & 14.717 & 15.425 & 0.359 & 15.035 \\
\hline & Downface & & 17.306 & 16.251 & 17.306 & 0.609 & 16.954 \\
\hline & Topface & & 12.778 & 9.888 & 15.136 & 2.628 & 12.601 \\
\hline \multirow{2}{*}{90} & Upface & \multirow{2}{*}{ - } & 12.304 & 11.678 & 13.541 & 0.948 & 12.508 \\
\hline & Downface & & 12.874 & 12.842 & 13.527 & 0.387 & 13.081 \\
\hline
\end{tabular}




\begin{tabular}{|c|c|c|c|c|c|c|c|}
\hline & Topface & & 3.087 & 2.644 & 4.274 & 0.843 & 3.335 \\
\hline \multirow{24}{*}{30} & \multirow{4}{*}{ r3- concave } & 180 & 15.980 & 15.200 & 15.180 & 0.456 & 15.453 \\
\hline & & 150 & 16.192 & 14.587 & 14.984 & 0.836 & 15.254 \\
\hline & & 120 & 13.664 & 14.621 & 13.898 & 0.499 & 14.061 \\
\hline & & 90 & 12.707 & 13.244 & 13.034 & 0.271 & 12.995 \\
\hline & \multirow{4}{*}{ r3 - convex } & 0 & 18.093 & 17.664 & 15.305 & 1.501 & 17.021 \\
\hline & & 30 & 13.837 & 12.527 & 13.227 & 0.656 & 13.197 \\
\hline & & 60 & 10.993 & 11.107 & 10.846 & 0.131 & 10.982 \\
\hline & & 90 & 13.838 & 13.541 & 15.113 & 0.835 & 14.164 \\
\hline & \multirow{4}{*}{ r2- concave } & 180 & 14.238 & 13.482 & 13.934 & 0.380 & 13.885 \\
\hline & & 150 & 13.765 & 13.676 & 14.809 & 0.630 & 14.083 \\
\hline & & 120 & 11.746 & 12.942 & 14.491 & 1.376 & 13.060 \\
\hline & & 90 & 12.330 & 10.023 & 10.746 & 1.180 & 11.033 \\
\hline & \multirow{4}{*}{ r2 - convex } & 0 & 16.391 & 16.257 & 16.573 & 0.159 & 16.407 \\
\hline & & 30 & 19.035 & 18.117 & 16.269 & 1.409 & 17.807 \\
\hline & & 60 & 10.687 & 10.835 & 11.180 & 0.253 & 10.901 \\
\hline & & 90 & 11.700 & 12.194 & 13.027 & 0.671 & 12.307 \\
\hline & \multirow{4}{*}{ r1- concave } & 180 & 15.554 & 15.746 & 15.124 & 0.318 & 15.475 \\
\hline & & 150 & & & & - & - \\
\hline & & 120 & & & & - & - \\
\hline & & 90 & 12.179 & 13.324 & 10.721 & 1.305 & 12.075 \\
\hline & \multirow{4}{*}{ r1 - convex } & 0 & & & & - & - \\
\hline & & 30 & & & & - & - \\
\hline & & 60 & & & & - & - \\
\hline & & 90 & & & & - & - \\
\hline \multirow{18}{*}{50} & \multirow{4}{*}{ r3- concave } & 180 & 20.408 & 20.435 & 18.894 & 0.882 & 19.912 \\
\hline & & 150 & 16.973 & 17.620 & 17.392 & 0.328 & 17.328 \\
\hline & & 120 & 15.688 & 17.703 & 16.826 & 1.010 & 16.739 \\
\hline & & 90 & 11.889 & 13.390 & 11.295 & 1.080 & 12.191 \\
\hline & \multirow{4}{*}{ r3 - convex } & 0 & 22.497 & 24.596 & 25.048 & 1.361 & 24.047 \\
\hline & & 30 & 17.643 & 17.082 & 19.144 & 1.066 & 17.956 \\
\hline & & 60 & 11.783 & 11.440 & 11.882 & 0.232 & 11.702 \\
\hline & & 90 & 13.901 & 14.743 & 15.954 & 1.032 & 14.866 \\
\hline & \multirow{4}{*}{$\mathrm{r} 2$ - concave } & 180 & 18.451 & 16.264 & 19.014 & 1.453 & 17.910 \\
\hline & & 150 & 16.198 & 16.886 & 20.335 & 2.217 & 17.806 \\
\hline & & 120 & 13.262 & 14.281 & 13.277 & 0.584 & 13.607 \\
\hline & & 90 & 11.105 & 10.336 & 10.424 & 0.421 & 10.622 \\
\hline & \multirow{4}{*}{ r2 - convex } & 0 & & & & - & - \\
\hline & & 30 & 19.082 & 21.708 & 20.057 & 1.327 & 20.282 \\
\hline & & 60 & 12.499 & 13.786 & 14.722 & 1.116 & 13.669 \\
\hline & & 90 & 13.985 & 12.804 & 13.558 & 0.598 & 13.449 \\
\hline & \multirow{2}{*}{ r1- concave } & 180 & 18.429 & 20.043 & 18.369 & 0.950 & 18.947 \\
\hline & & 150 & & & & - & - \\
\hline
\end{tabular}




\begin{tabular}{|c|c|c|c|c|c|c|c|}
\hline & & 120 & & & & - & - \\
\hline & & 90 & 14.371 & 14.566 & 14.137 & 0.215 & 14.358 \\
\hline & \multirow{4}{*}{ r1 - convex } & 0 & 26.016 & 25.445 & 28.990 & 1.903 & 26.817 \\
\hline & & 30 & 20.020 & 19.638 & 18.529 & 0.774 & 19.396 \\
\hline & & 60 & & & & - & - \\
\hline & & 90 & & & & - & - \\
\hline \multirow{24}{*}{70} & \multirow{4}{*}{ r3- concave } & 180 & 16.238 & 14.125 & 16.070 & 1.174 & 15.478 \\
\hline & & 150 & 17.280 & 16.980 & 17.287 & 0.175 & 17.182 \\
\hline & & 120 & 13.136 & 13.531 & 16.110 & 1.615 & 14.259 \\
\hline & & 90 & 13.442 & 13.608 & 11.963 & 0.906 & 13.004 \\
\hline & & 0 & & & & - & - \\
\hline & $r^{2} \quad$ onvor & 30 & & & & - & - \\
\hline & IJ - Comvex & 60 & & & & - & - \\
\hline & & 90 & 10.980 & 11.035 & 9.352 & 0.956 & 10.456 \\
\hline & & 180 & 16.497 & 17.957 & 16.726 & 0.785 & 17.060 \\
\hline & n 2 comoryo & 150 & 15.923 & 17.777 & 15.089 & 1.376 & 16.263 \\
\hline & 1z-concave & 120 & 11.438 & 12.302 & 13.881 & 1.239 & 12.540 \\
\hline & & 90 & 10.494 & 11.771 & 10.642 & 0.698 & 10.969 \\
\hline & & 0 & & & & - & - \\
\hline & r2 - convex & 30 & 26.634 & 23.999 & 22.687 & 2.010 & 24.440 \\
\hline & 12-convex & 60 & 18.667 & 18.596 & 18.623 & 0.036 & 18.629 \\
\hline & & 90 & 10.251 & 10.272 & 10.747 & 0.281 & 10.423 \\
\hline & & 180 & 19.396 & 20.733 & 19.333 & 0.791 & 19.821 \\
\hline & r1-concave & 150 & & & & - & - \\
\hline & 11-concave & 120 & & & & - & - \\
\hline & & 90 & 18.016 & 14.925 & 17.852 & 1.739 & 16.931 \\
\hline & & 0 & & & & - & - \\
\hline & r1 conyey & 30 & & & & - & - \\
\hline & 11-comvex & 60 & & & & - & - \\
\hline & & 90 & & & & - & - \\
\hline & & 180 & 6.011 & 4.721 & 4.304 & 0.890 & 5.012 \\
\hline & r3-concave & 150 & & & & - & - \\
\hline & rs-concave & 120 & & & & - & - \\
\hline & & 90 & & & & - & - \\
\hline & & 0 & & & & - & - \\
\hline & r3 - convex & 30 & & & & - & - \\
\hline 90 & & 60 & & & & - & - \\
\hline & & 90 & & & & - & - \\
\hline & & 180 & 11.229 & 6.030 & 5.479 & 3.173 & 7.579 \\
\hline & r2-concave & 150 & 13.275 & 15.191 & 19.914 & 3.417 & 16.127 \\
\hline & 1z-concave & 120 & 14.220 & 14.350 & 15.054 & 0.449 & 14.541 \\
\hline & & 90 & 11.540 & 10.619 & 10.595 & 0.539 & 10.918 \\
\hline & r2 - convex & 0 & & & & - & - \\
\hline
\end{tabular}




\begin{tabular}{|c|c|c|c|c|c|c|}
\hline & 30 & 23.795 & 19.996 & 30.120 & 5.114 & 24.637 \\
\hline & 60 & 14.242 & 19.036 & 24.210 & 4.985 & 19.163 \\
\hline & 90 & 12.856 & 15.867 & 11.671 & 2.163 & 13.465 \\
\hline \multirow{4}{*}{ r1- concave } & 180 & 11.693 & 15.602 & 16.108 & 2.416 & 14.468 \\
\hline & 150 & & & & - & - \\
\hline & 120 & & & & - & - \\
\hline & 90 & 10.814 & 10.931 & 11.344 & 0.278 & 11.030 \\
\hline \multirow{4}{*}{ r1 - convex } & 0 & & & & - & - \\
\hline & 30 & & & & - & - \\
\hline & 60 & & & & - & - \\
\hline & 90 & & & & - & - \\
\hline
\end{tabular}

Table 11. Surface profilometer measurements of $R a$ for each feature on benchmark specimen v2 built with contour set 5 .

\begin{tabular}{|c|c|c|c|c|c|c|c|}
\hline \multicolumn{3}{|c|}{ Feature } & \multicolumn{5}{|c|}{$\operatorname{Ra}(\mu \mathrm{m})$} \\
\hline $\begin{array}{c}\text { Overhang } \\
\text { Angle }\end{array}$ & Hole/Plane & $\begin{array}{c}\text { Side \& } \\
\text { Angle }\end{array}$ & Run 1 & Run 2 & Run 3 & STD DEV & AVG \\
\hline \multirow{3}{*}{30} & Upface & \multirow{3}{*}{-} & 17.263 & 22.957 & 16.402 & 3.562 & 18.874 \\
\hline & Downface & & & & & - & - \\
\hline & Topface & & 13.934 & 15.770 & 10.286 & 2.791 & 13.330 \\
\hline \multirow{3}{*}{50} & Upface & \multirow{3}{*}{-} & 16.393 & 14.279 & 18.387 & 2.054 & 16.353 \\
\hline & Downface & & 23.592 & 27.598 & 23.206 & 2.432 & 24.799 \\
\hline & Topface & & 12.888 & 12.216 & 14.431 & 1.136 & 13.178 \\
\hline \multirow{3}{*}{70} & Upface & \multirow{3}{*}{-} & 14.549 & 14.427 & 13.984 & 0.297 & 14.320 \\
\hline & Downface & & 16.580 & 12.599 & 14.289 & 1.998 & 14.489 \\
\hline & Topface & & 10.859 & 17.668 & 12.108 & 3.625 & 13.545 \\
\hline \multirow{3}{*}{90} & Upface & \multirow{3}{*}{-} & 11.718 & 11.187 & 11.852 & 0.352 & 11.586 \\
\hline & Downface & & 10.727 & 9.761 & 12.750 & 1.525 & 11.079 \\
\hline & Topface & & 3.643 & 3.127 & 3.187 & 0.282 & 3.319 \\
\hline \multirow{12}{*}{30} & \multirow{4}{*}{ r3- concave } & 180 & 14.088 & 13.799 & 17.572 & 2.100 & 15.153 \\
\hline & & 150 & 14.760 & 16.105 & 17.048 & 1.150 & 15.971 \\
\hline & & 120 & 13.776 & 12.128 & 12.562 & 0.854 & 12.822 \\
\hline & & 90 & 14.137 & 13.460 & 13.500 & 0.380 & 13.699 \\
\hline & \multirow{4}{*}{ r3 - convex } & 0 & 14.272 & 13.869 & 14.565 & 0.349 & 14.235 \\
\hline & & 30 & 15.734 & 12.045 & 12.547 & 2.001 & 13.442 \\
\hline & & 60 & 11.561 & 11.576 & 11.548 & 0.014 & 11.562 \\
\hline & & 90 & 13.328 & 12.442 & 11.688 & 0.821 & 12.486 \\
\hline & \multirow{4}{*}{ r2- concave } & 180 & 17.820 & 17.148 & 17.718 & 0.362 & 17.562 \\
\hline & & 150 & 15.901 & 15.695 & 12.821 & 1.722 & 14.806 \\
\hline & & 120 & 12.893 & 13.101 & 12.994 & 0.104 & 12.996 \\
\hline & & 90 & 13.592 & 14.944 & 12.303 & 1.321 & 13.613 \\
\hline
\end{tabular}




\begin{tabular}{|c|c|c|c|c|c|c|c|}
\hline & \multirow{4}{*}{ r2 - convex } & 0 & 16.009 & 16.592 & 17.085 & 0.539 & 16.562 \\
\hline & & 30 & 14.248 & 14.577 & & 0.233 & 14.413 \\
\hline & & 60 & 13.520 & 12.649 & 11.699 & 0.911 & 12.623 \\
\hline & & 90 & 15.368 & 15.986 & 15.986 & 0.357 & 15.780 \\
\hline & \multirow{4}{*}{ r1- concave } & 180 & 15.050 & 14.792 & 14.915 & 0.129 & 14.919 \\
\hline & & 150 & & & & - & - \\
\hline & & 120 & & & & - & - \\
\hline & & 90 & 13.032 & 12.294 & 12.177 & 0.464 & 12.501 \\
\hline & \multirow{4}{*}{ r1 - convex } & 0 & 16.651 & 16.582 & 16.435 & 0.110 & 16.556 \\
\hline & & 30 & 16.675 & 17.109 & 15.165 & 1.020 & 16.316 \\
\hline & & 60 & 11.278 & 11.656 & 11.954 & 0.339 & 11.629 \\
\hline & & 90 & & & & - & - \\
\hline \multirow{24}{*}{50} & \multirow{4}{*}{ r3- concave } & 180 & 18.380 & 18.992 & 18.460 & 0.333 & 18.611 \\
\hline & & 150 & 18.148 & 17.228 & 15.892 & 1.134 & 17.089 \\
\hline & & 120 & 14.510 & 14.937 & 13.865 & 0.540 & 14.437 \\
\hline & & 90 & 12.623 & 12.351 & 12.932 & 0.291 & 12.635 \\
\hline & \multirow{4}{*}{ r3 - convex } & 0 & 24.725 & 23.729 & 25.665 & 0.968 & 24.706 \\
\hline & & 30 & 20.779 & 17.816 & 22.010 & 2.156 & 20.202 \\
\hline & & 60 & 12.079 & 16.424 & 12.786 & 2.331 & 13.763 \\
\hline & & 90 & 11.328 & 12.280 & 13.718 & 1.203 & 12.442 \\
\hline & \multirow{4}{*}{ r2- concave } & 180 & 20.994 & 20.009 & 17.354 & 1.883 & 19.452 \\
\hline & & 150 & 14.692 & 17.539 & 17.160 & 1.546 & 16.464 \\
\hline & & 120 & 13.103 & 12.526 & 13.308 & 0.405 & 12.979 \\
\hline & & 90 & 13.158 & 12.711 & 13.601 & 0.445 & 13.157 \\
\hline & \multirow{4}{*}{ r2 - convex } & 0 & 21.485 & 23.450 & & 1.389 & 22.468 \\
\hline & & 30 & 24.799 & 21.277 & 23.338 & 1.769 & 23.138 \\
\hline & & 60 & 16.689 & 13.879 & 12.678 & 2.059 & 14.415 \\
\hline & & 90 & 12.129 & 11.497 & 12.225 & 0.396 & 11.950 \\
\hline & \multirow{4}{*}{ r1- concave } & 180 & 21.209 & 21.209 & 17.564 & 2.104 & 19.994 \\
\hline & & 150 & & & & - & - \\
\hline & & 120 & & & & - & - \\
\hline & & 90 & 16.577 & 16.546 & 16.829 & 0.155 & 16.651 \\
\hline & \multirow{4}{*}{ r1 - convex } & 0 & & & & - & - \\
\hline & & 30 & 22.438 & 25.309 & 23.122 & 1.500 & 23.623 \\
\hline & & 60 & & & & - & - \\
\hline & & 90 & & & & - & - \\
\hline \multirow{7}{*}{70} & \multirow{4}{*}{ r3- concave } & 180 & 16.065 & 16.490 & 14.635 & 0.972 & 15.730 \\
\hline & & 150 & 14.313 & 18.284 & 16.028 & 1.992 & 16.208 \\
\hline & & 120 & 12.226 & 12.932 & 11.170 & 0.887 & 12.109 \\
\hline & & 90 & 10.796 & 11.586 & 10.513 & 0.556 & 10.965 \\
\hline & \multirow{3}{*}{ r3 - convex } & 0 & & & & - & - \\
\hline & & 30 & & & & - & - \\
\hline & & 60 & 12.676 & 11.970 & 9.791 & 1.504 & 11.479 \\
\hline
\end{tabular}




\begin{tabular}{|c|c|c|c|c|c|c|c|}
\hline & & 90 & 10.879 & 10.805 & 12.090 & 0.721 & 11.258 \\
\hline & \multirow{4}{*}{ r2- concave } & 180 & 14.877 & 15.079 & 19.735 & 2.748 & 16.564 \\
\hline & & 150 & 14.988 & 17.191 & 18.478 & 1.765 & 16.886 \\
\hline & & 120 & 14.133 & 13.177 & 13.997 & 0.517 & 13.769 \\
\hline & & 90 & 11.374 & 13.102 & 10.443 & 1.349 & 11.640 \\
\hline & \multirow{4}{*}{ r2 - convex } & 0 & & & & - & - \\
\hline & & 30 & & & & - & - \\
\hline & & 60 & 11.251 & 13.232 & 14.041 & 1.435 & 12.841 \\
\hline & & 90 & 11.399 & 11.875 & 11.063 & 0.408 & 11.446 \\
\hline & \multirow{4}{*}{ r1- concave } & 180 & 13.463 & 15.809 & 16.222 & 1.488 & 15.165 \\
\hline & & 150 & & & & - & - \\
\hline & & 120 & & & & - & - \\
\hline & & 90 & 18.940 & 21.134 & 21.132 & 1.266 & 20.402 \\
\hline & \multirow{4}{*}{ r1 - convex } & 0 & & & & - & - \\
\hline & & 30 & 24.389 & 26.630 & 21.615 & 2.512 & 24.211 \\
\hline & & 60 & & & & - & - \\
\hline & & 90 & & & & - & - \\
\hline \multirow{24}{*}{90} & \multirow{4}{*}{ r3- concave } & 180 & 13.078 & 15.409 & 12.841 & 1.419 & 13.776 \\
\hline & & 150 & & & & - & - \\
\hline & & 120 & & & & - & - \\
\hline & & 90 & & & & - & - \\
\hline & \multirow{4}{*}{ r3 - convex } & 0 & & & & - & - \\
\hline & & 30 & & & & - & - \\
\hline & & 60 & & & & - & - \\
\hline & & 90 & & & & - & - \\
\hline & \multirow{4}{*}{ r2- concave } & 180 & 5.412 & 6.496 & 6.360 & 0.591 & 6.089 \\
\hline & & 150 & 13.808 & 15.066 & 14.964 & 0.699 & 14.613 \\
\hline & & 120 & 16.347 & 10.989 & 11.220 & 3.029 & 12.852 \\
\hline & & 90 & 13.392 & 13.076 & 11.536 & 0.993 & 12.668 \\
\hline & \multirow{4}{*}{ r2 - convex } & 0 & & & & - & - \\
\hline & & 30 & & & & - & - \\
\hline & & 60 & 16.398 & 12.479 & 12.469 & 2.266 & 13.782 \\
\hline & & 90 & 10.040 & 12.048 & 12.645 & 1.365 & 11.578 \\
\hline & \multirow{4}{*}{ r1- concave } & 180 & 11.482 & 12.452 & 10.457 & 0.998 & 11.464 \\
\hline & & 150 & & & & - & - \\
\hline & & 120 & & & & - & - \\
\hline & & 90 & 18.701 & 19.966 & 18.360 & 0.846 & 19.009 \\
\hline & \multirow{4}{*}{ r1 - convex } & 0 & & & & - & - \\
\hline & & 30 & 30.934 & 22.411 & 21.783 & 5.112 & 25.043 \\
\hline & & 60 & & & & - & - \\
\hline & & 90 & & & & - & - \\
\hline
\end{tabular}




\section{CURRICULUM VITAE}

NAME: $\quad$ Katherine Grace Schneidau

ADDRESS: 1802 Integrity Way, Unit 102

Louisville, KY 40220

DOB: $\quad$ Rochester Hills, Michigan - July 9, 1996

EDUCATION

\& TRAINING: $\quad$ B.S., Mechanical Engineering

University of Louisville

2016-2019

AWARDS: $\quad$ Guy E. Bordeau Scholarship - Additive Manufacturing Users' Group 2020

PROFESSIONAL SOCIETITES:

PUBLICATIONS:

NATIONAL MEETING PRESENTATIONS

REFERRED JOURNALS

BOOKS AND SYMPOSIA

INVITED PRESENTATIONS 